\title{
A novel enhancer of Agouti contributes to parallel evolution of cryptically colored beach mice
}

\author{
T. Brock Wooldridge ${ }^{1}$, Andreas F. Kautt ${ }^{1}$, Jean-Marc Lassance ${ }^{1}$, Sade McFadden ${ }^{1}$, Vera S. \\ Domingues $^{1 *}$, Ricardo Mallarino ${ }^{2}$, Hopi E. Hoekstra ${ }^{1}$ \\ ${ }^{1}$ Department of Organismic \& Evolutionary Biology, Department of Molecular \& Cellular Biology, Museum of \\ Comparative Zoology, Howard Hughes Medical Institute, Harvard University, 16 Divinity Avenue, Cambridge, \\ MA 02138, USA. \\ ${ }^{2}$ Department of Molecular Biology, 119 Lewis Thomas Laboratory, Washington Road, Princeton University, \\ Princeton, NJ 08544, USA. \\ ${ }^{*}$ Current Address: Nature Ecology \& Evolution, 4 Crinan Street, London N1 9XW, UK. \\ Correspondence to: hoekstra@oeb.harvard.edu
}

\begin{abstract}
Identifying the genetic basis of repeatedly evolved traits provides a way to reconstruct their evolutionary history and ultimately investigate the predictability of evolution. Here, we focus on the oldfield mouse (Peromyscus polionotus), which occurs in the southeastern United States, where it exhibits considerable coat-color variation. Dorsal coats range from dark brown in mice inhabiting mainland habitat to near white on the white-sand beaches of the southeastern US, where light pelage has evolved independently on Florida's Gulf and Atlantic coasts as an adaptation to visually hunting predators. To facilitate genomic analyses in this species, we first generated a high-quality, chromosome-level genome assembly of $P$. polionotus subgriseus. Next, in a uniquely variable mainland population that occurs near beach habitat (P. p. albifrons), we scored 23 pigment traits and performed targeted resequencing in 168 mice. We find that variation in pigmentation is strongly associated with a $\sim 2 \mathrm{~kb}$ region approximately 5 $\mathrm{kb}$ upstream of the Agouti-signaling protein (ASIP) coding region. Using a reporter-gene assay, we demonstrate that this regulatory region contains an enhancer that drives expression in the dermis of mouse embryos during the establishment of pigment prepatterns. Moreover, extended tracts of homozygosity in this region of Agouti indicate that the light allele has experienced recent and strong positive selection. Notably, this same light allele appears fixed in both Gulf and Atlantic coast beach mice, despite these populations being separated by $>1,000 \mathrm{~km}$. Given the evolutionary history of this species, our results suggest that this newly identified Agouti enhancer allele has been maintained in mainland populations as standing genetic variation and from there has spread to, and been selected in, two independent beach mouse lineages, thereby facilitating their rapid and parallel evolution.
\end{abstract}

Keywords: adaptation, camouflage, crypsis, deer mice, enhancer, pelage, pigmentation 
To gain a complete picture of adaptation, we strive to understand both the molecular mechanisms and the evolutionary processes underlying trait evolution. On one hand, identifying the molecular basis of phenotypic adaptation can provide an opportunity to learn how traits vary - in particular, how specific changes in DNA can affect protein function or expression during development to produce the trait of interest. On the other hand, the evolutionary history of a specific allele can provide insights into when and why traits evolve. Importantly, an allele may be influenced by a combination of neutral and selective forces, which together explain its current distribution and frequency. Thus, the identification of a causal gene, or better, a small gene region or mutation, can serve as a handle with which to probe both the proximate (how) and ultimate (when/why) drivers of trait variation.

Cases of repeated evolution provide a particularly appealing context for understanding the drivers of adaptation. For example, one can ask: did similar phenotypes arise via the same or different molecular changes? While there are empirical examples of selection from new mutations (e.g., Chan et al., 2010; Kowalko et al., 2013; Linnen et al., 2009), it has been suggested that rapid adaptation, in particular within species, may be fueled by selection on the same alleles from pre-existing genetic variation (e.g., Conte et al., 2012; Jones et al., 2018; Oziolor et al., 2019; reviewed in Barrett and Schluter, 2008). Moreover, it has been argued that changes in cis-regulatory elements may be the primary substrate of adaptation (Carroll, 2008; Stern and Orgogozo, 2009; Wittkopp and Kalay, 2011), although many examples of protein-coding changes (e.g., Hoballah et al., 2007; Projecto-Garcia et al., 2013; Zhen et al., 2012; reviewed in Hoekstra and Coyne, 2007) or combinations of both regulatory and coding changes (e.g., Vickrey et al., 2018) have been identified. Nonetheless, when regulatory change has been implicated in repeated evolution, it is still rare that the causal regions, elements, or mutations have been identified (but see Chan et al., 2010; Lewis et al., 2019). This is in part due to the complexity of gene regulatory landscapes and the relative difficulty in testing the effects of a non-coding allele (Pai et al., 2015). By contrast, coding mutations are generally more amenable to identification and functional validation; therefore, when precise mutations have been shown to drive repeated evolution across species, they most commonly correspond to coding mutations (see Martin and Orgogozo, 2013). Thus, it remains difficult to determine the extent to which similar or different mutations contribute to repeated phenotypic evolution and where in the genome they occur.

Variation in pigmentation has long served as a model for the study of adaptation. At the molecular level, the genes and pathways involved in vertebrate pigmentation have been well characterized (Hoekstra 2006). At the phenotypic level, color can vary dramatically in the wild, can be measured straightforwardly, and can have clear links to fitness (e.g., Caro and Mallarino, 2019). One classic and extreme example of rapid color evolution involves the beach mice found in the southeastern United States. There, local populations have independently evolved light coloration on Florida's Gulf and Atlantic Coasts from a dark-colored mainland ancestor (Steiner et al., 2009). Previous work identified three genomic regions involved in differences between beach and mainland mice (Steiner et al., 2007), which were subsequently localized to three pigmentation genes: the Melanocortin-1 receptor $(\mathrm{Mc} 1 \mathrm{r})$, Agouti signaling protein (ASIP), and Corin (Hoekstra et al., 2006; Manceau et al., 2011; Manceau et al., in review). In mammals, the interaction between $M c 1 r$ and its inverse agonist Agouti mediates the switch from dark (eumelanin) to light pigment (pheomelanin) production (Barsh, 1996; Ollmann et al., 1998; Vrieling et al., 1994), while their interaction with Corin, in turn, can mediate the fine-tuning of pigment patterns (Enshell-seijffers et al., 2008; Manceau et al., in review). In Gulf Coast beach mice, a single missense mutation in Mclr, together with cis-regulatory changes in Agouti (as well as Corin) together are largely responsible for their light pigmentation. Therefore, changes in genes at multiple levels of the pigment pathway have been implicated in the evolution of camouflaging coloration in Gulf Coast beach mice.

In contrast, the genes (and mutations) contributing to light coats of the Atlantic coast beach mice have remained elusive. For example, the Mclr amino acid change found in Gulf Coast mice is absent from 
Atlantic coast mice (Hoekstra et al., 2006), and no new Mclr mutations are associated with color variation or have a measurable effect on Mc1r function (Steiner et al., 2009). In addition, there are no differences in the Agouti coding region between mainland mice and beach mice on either coast (Steiner et al., 2007). While this implies a likely role for regulatory changes, the precise regulatory elements(s) and mutation(s) driving cis-acting differences in Agouti expression in Gulf beach mice, and possibly Atlantic mice, have not yet been identified. As a result, it remains an outstanding question whether the similarly light-colored Gulf and Atlantic Coast beach mice carry the same or distinct pigmentation alleles.

Here we return to the classic case of adaptation in Gulf and Atlantic Coast beach mice, first described over a century ago (Howell, 1920; Sumner, 1926) and capitalize on naturally occurring color variation in a single mainland population to identify the molecular basis of adaptation, using the first chromosomelevel genome assembly for $P$. polionotus. Specifically, we employ an association-mapping approach to identify a $\sim 2 \mathrm{~kb}$ previously uncharacterized non-coding region of Agouti associated with color variation. We then show that this $2 \mathrm{~kb}$ region can drive dermal expression in Mus embryos, demonstrating its regulatory activity in the skin during the establishment of pigmentation. Finally, we reveal the evolutionary history of this regulatory element to show both strong selection on the light Agouti allele in a phenotypically variable population, and that this same allele is fixed in beach mice of both the Gulf and Atlantic Coasts. Together we find both the molecular basis and evolutionary history differs markedly between two key genes involved in beach mouse adaptation - Agouti and Mclr-highlighting that there can be multiple genetic solutions to the same ecological challenge, even within species.

\section{Results}

Assembly of a high quality, chromosome-level genome for $\boldsymbol{P}$. polionotus

We generated whole-genome sequencing (WGS) data and assembled a de novo high-quality reference genome for the oldfield mouse, Peromyscus polionotus subgriseus (BioProject number PRJNA494229). The final genome was $2.645 \mathrm{~Gb}$ in length with a N50 scaffold length of $13 \mathrm{Mb}$. We could anchor $97 \%$ of the de novo assembled bases into 23 autosomes and the $\mathrm{X}$ chromosome using high-density genetic linkage maps for Peromyscus. Our estimates indicate that the assembly contains $95.4 \%$ and $94.8 \%$ of single-copy core mammalian and euarchontoglire genes, respectively. Our annotation strategy, which combined comparative in silico and evidence-based approaches, identified 18,502 protein-coding genes having orthologs in the Mus genome, 536 paralogs of Mus genes and 1,912 additional genes showing homology with known proteins from curated databases. This complete, high-quality genome enables evolutionary analyses of genome-wide variation across populations of this species.

\section{Recent and independent evolution of beach mice on the Gulf and Atlantic coasts}

To better estimate the timing and pattern of divergence in the beach and mainland subspecies (Fig. 1A), we sampled six beach and five mainland populations, representing nine of the fourteen extant $P$. polionotus subspecies (Fig. 1B) as well as the closely related sister species, $P$. maniculatus nubiterrae. Using 1000 randomly distributed genome-wide SNPs derived from putatively neutral regions in a targeted sequence-capture dataset, we generated a highly supported phylogeny confirming the independent origin of beach mice in the Gulf and Atlantic coasts from an ancestral mainland form (Fig. 1C), consistent with previous studies (Domingues et al., 2012; Kalkvik et al., 2018; Mullen et al., 2009; Steiner et al., 2009). The Gulf Coast beach mice form a paraphyletic group with adjacent mainland populations, all of which share a common ancestor between 3.5-7.2 thousand years ago (kya). Similarly, the Atlantic Coast beach mice share a common ancestor with their closest mainland counterparts 2.9-6.4 kya, suggesting that both Gulf and Atlantic beach lineages originated at approximately the same time. In general, we find that the relationships of subspecies in the phylogeny mirrors their geographic distribution, a pattern that is supported by a genetic Principal Components Analysis based on genotype likelihoods from all loci in the sequence-capture dataset (gPCA; Fig. 1D). The evolutionary history of both Gulf and Atlantic beach mice 
as well as several mainland populations provides a demographic context in which to understand the evolution of crypsis.

\section{Phenotypic variation in a single mainland population ( $P$. p. albifrons)}

We sampled one mainland population neighboring beach habitat, $P$. p. albifrons, that exhibited a wide range of coat colors - from light and sparsely pigmented coats similar to those of beach mice to the dark and extensively pigmented coats typical of mainland mice. To better characterize and quantify this variation, we measured 23 coat-color traits in 168 skin specimens of $P$. p. albifrons (Fig. 2A). All traits were related to either the distribution of pigmentation (e.g., tail-stripe length) or intensity of pigment (e.g., dorsal hue, brightness) and are known to vary among beach mouse populations (Steiner et al., 2009). To establish reference points with which to compare the albifrons population, we scored the same 23 traits in representative mice from Gulf, Atlantic, and mainland subspecies (Table S1).

We found that many pigment traits are highly correlated in the albifrons population (Fig. 2B). A principal components analysis (PCA) shows that six traits - dorsal brightness, tail-stripe length and the extent of pigmentation on the cheek, rump, whisker, and ankle - heavily load on phenotypic PC1 (pPC1), and that a specimen's pPC1 score is a strong predictor of overall lightness or darkness (Fig. 2B, Fig. S1). Remaining traits also form distinct clusters, but none of these additional clusters encompass as many traits as pPC1 or show the same strength of association with overall coloration (Fig. 2B). The highest pPC1 values observed in the population represent the darkest mice, which are similar in appearance (and pPC1 score) to the mainland subspecies, P. p. polionotus (Fig. 2C). And while the lightest albifrons individuals are still darker than the geographically proximate beach subspecies $P$. p. leucocephalus - the palest form of the Gulf beach mice - many individuals with intermediate pPC1 scores are comparable to a typical Atlantic beach mouse (e.g., P. p. niveiventris; Fig. 2C). Despite this range in coloration that encompasses both beach and mainland phenotypes, none of these pigment traits show a significant association with population structure, not surprising given that the $P$. $p$ albifrons population has little detectable genetic structure (Fig. S2).

\section{Association between pigmentation and a non-coding region of $\mathrm{Agouti}$}

Capitalizing on the extensive color variation observed within the panmictic albifrons population, we performed single-variant association mapping using the sequence-capture data from this population. These data include 6547 putatively neutral biallelic SNPs from across the genome as well as the genomic regions encompassing two pigmentation genes, Agouti and $M c 1 r(190 \mathrm{~kb}$ and $150 \mathrm{~kb}$ in length, respectively, which includes all exons and known regulatory regions). In our scan, we detected a single region associated with $\mathrm{pPC} 1$ that exceeded the genome-wide significance threshold $\left(\mathrm{p}<1.23 \times 10^{-5}\right.$ corrected for number of effective tests; Fig. 3A) in the Agouti locus. A closer investigation of this region revealed three SNPs significantly associated with pigment variation, spanning $1,756 \mathrm{bp}$, in strong linkage disequilibrium (mean $\mathrm{r}^{2}=0.85$ ). A single SNP at position chr4:9,845,301 showed a markedly stronger association with pPC1 than the other two (Fig. 3B). This SNP is located between two untranslated exons (exons 1D and 1E), is 120bp upstream of a cluster of SINE elements in reverse orientation relative to the transcription of Agouti, and is 5,641 bp upstream of the first coding exon (exon 2). Genotype-phenotype regressions show an additive effect of this locus, which explains $36 \%$ of the variance in pPC1, as well as a substantial degree of additive variation in pPC1-correlated traits such as dorsal brightness (19\%) or tail stripe length (7.2\%) (Fig. 3C). Together, these data point to a small non-coding region of Agouti, containing a mutation(s) having a major effect on variation in overall pigmentation in P. p. albifrons.

\section{The candidate Agouti region is capable of regulatory activity}

To determine if this $\sim 2 \mathrm{~kb}$ Agouti region associated with $\mathrm{pPC} 1$ is capable of regulatory activity, we first determined whether the region overlaps with known regulatory elements (Fig. 4A). In the homologous region and $\pm 10 \mathrm{~kb}$ surrounding sequence in $M u s$, we observe few known regulatory elements, none of which are associated with dermal tissues (Table S2). Moreover, it does not overlap with 
any previously identified regions associated with pigment variation in other Peromyscus species (e.g., Linnen et al., 2013; Fig. S3). As sequence conservation can be indicative of conserved molecular function, we next examined sequence similarity across 27 rodents in the $5 \mathrm{~kb}$ upstream and downstream of the top associated SNP (which also includes the two linked variants and SINE elements). Surprisingly, conservation within rodents was minimal, with only a subset of the species - the superfamily Muroidea showing greater than $50 \%$ sequence similarity for the majority of the region (Fig. 4B; Figure S4). These data suggest that if this region has regulatory function, it is likely to have evolved recently.

To assess whether the candidate region of Agouti contains functional enhancers, we cloned a $2.6 \mathrm{~kb}$ sequence that spans $0.5 \mathrm{~kb}$ upstream and $2.1 \mathrm{~kb}$ downstream of the most strongly associated variant (i.e., chr4:9,845,301) and includes the two additional associated variants (chr4:9,845,152, chr4: 9,846,908) as well as a small downstream region conserved in rodents (Fig. 4B, Fig. S5). We then inserted this sequence upstream of a minimal promoter and $l a c Z$ reporter gene (Fig. 4C). Given the currently limited transgenic techniques available for Peromyscus, the resulting construct was injected into embryos of Mus (strain FVB/NJ), and embryos were collected at stage E14.5, a timepoint when Agouti expression plays a key role in the establishment of pigment prepatterns in both Mus and Peromyscus (Manceau et al., 2011). Of the 14 embryos with independent genomic integrations of the lac $Z$ construct (verified by PCR), we observed consistent $l a c Z$ expression in the skin of eight embryos, although expression was spatially variable across embryos (Fig. 4D; Fig. S5). Histological analysis showed that lacZ was localized to the dermis, corresponding to the known site of endogenous Agouti expression during embryonic development (Fig. 4E). Together, the results of these experiments suggest that this previously undescribed $\sim 2 \mathrm{~kb}$ noncoding region contains a cis-regulatory element (or possibly multiple elements constituting a cisregulatory module) capable of driving Agouti dermal expression during embryonic development.

\section{The light Agouti allele shows a signature of positive selection}

We next tested if there was evidence of natural selection acting on the light-associated allele at this regulatory element, which is found at $86 \%$ frequency in the albifrons population (Table S3). In the region surrounding the top associated SNP (chr4:9,845,301), we found that haplotype homozygosity decays more quickly for the dark allele than for the light allele, a signal consistent with recent positive selection for light pigmentation (Fig. 5A). This signal of elevated homozygosity is statistically significant, with all three candidate SNPs identified in our association analysis (as well as 15 additional SNPs in this region) showing a significantly positive integrated haplotype score (IHS, p $<0.05$; Fig. 5B). We did not detect a signal of selection at these candidate SNPs in any other population, although low sample sizes and lack of polymorphisms limit our power. Together, these data support the hypothesis that natural selection, most likely on light coloration, has led to an increase in light Agouti allele frequency in the P. p. albifrons population.

\section{The light Agouti allele is fixed in both Gulf and Atlantic beach mouse populations}

Given the evidence for non-neutral evolution at this newly identified Agouti regulatory element, we next aimed to infer whether it exhibits a unique evolutionary history relative to the rest of the genome. Using Saguaro (Zamani et al. 2013), we generated local phylogenies in variably sized genomic windows across the Agouti locus for the combined dataset of beach and mainland populations, and then compared these phylogenies to the population tree constructed from genome-wide neutral loci. At Agouti, we find that much of the locus fits a topology (cactus 6) that coarsely mirrors the population-level phylogeny (Fig. 5). In contrast, one unique topology (cactus 4) is exclusively derived from two small regions that include the top-associated SNP and closely match the regulatory element identified in our mapping experiment (i.e., chr4:9,841,443 - 9,842,079 and chr4:9,844,852 - 9,847,023; Fig 5C). This unique topology clusters all individuals homozygous for Agouti light alleles into a single clade with short branch lengths, consistent with a recent origin for this allele, while all dark allele individuals fall into a clade with longer branch lengths similar to that observed in the population tree (Fig. 5D). Therefore, not only does this unsupervised approach identify the same region of Agouti as was localized in both the independent association and selection analyses, but it also points to a single origin for the light Agouti allele. These 
results show that the light Agouti allele arose once and is now shared by both the Gulf and Atlantic beach mice, even though these lineages are geographically distant and independently colonized their respective beach environments from mainland ancestors. This scenario, in which the same allele is inherited from a common ancestor and repeatedly selected for in multiple lineages, suggests that parallel genotypic evolution (sensu Rosenblum et al., 2014) has been an important factor in the evolution of beach mouse coloration.

\section{Discussion}

The question of how adaptation proceeds at the molecular level, and how predictable the process is, has long been of interest to evolutionary biologists. Debate around, for example, the locus of adaptation (i.e., coding versus regulatory mutations), the source of adaptive mutations (i.e., de novo mutations versus pre-existing variation) and the repeatability of this process (i.e., do the same or different mutations lead to similar, independently evolved traits) has been lively (e.g., Barrett and Schluter, 2008; Bolnik et al., 2018; Hoekstra and Coyne, 2007; Manceau et al., 2010; Martin and Orgogozo, 2013; Rosenblum et al., 2014; Stern and Orgogozo, 2008). Here, we provide insight into these questions from a classic system, first described over a century ago (Howell 1920): the recent adaptation of two independent lineages of beach mice to novel white-sand habitat through the evolution of camouflaging color. While the Agouti gene has been shown to contribute to the evolution of Gulf beach mouse color pattern through changes affecting both its expression level (Steiner et al., 2007) and spatial domain (Manceau et al., 2011), the molecular basis of these regulatory changes remained unclear. Furthermore, without information about the underlying regulatory region(s), the question of whether the genetic basis of light pigment in the Gulf and Atlantic Coast beach mice was the same or different was unknowable. Here, we uncovered a novel regulatory element in the Agouti gene and provide evidence that an allele of this element is associated with lighter pigmentation, and that it has been selected repeatedly from standing genetic variation in both lineages of beach mice.

To identify mutation(s) that contribute to changes in pigmentation, we first identified a population ( $P$. p. albifrons) that was phenotypically variable, ranging from light beach to dark mainland coat color. While most populations show little variation in pigmentation, this mainland population appears unique, likely because of its geographic proximity $(\sim 25 \mathrm{~km})$ to the beach habitat, its patchwork of light sandy and dark loamy soil, and intermediate level of vegetative cover relative to the open beach and dense mainland oldfield habitats. By conducting genetic association mapping in this variable population, we were able to narrow in on a small - approximately $2 \mathrm{~kb}$ - non-coding region which is strongly associated with overall pigmentation. This region having a causal effect on pigmentation is bolstered by two additional results: (1) its ability to drive expression in the dermis of Mus embryos at a stage when relevant to the establishment of pigmentation prepatterns, and (2) patterns of DNA polymorphism show a strong signature of positive selection in this same small region. Interestingly, this region had not been previously identified as functionally important in Mus (Vrieling et al., 1994) or Peromyscus sp. (Linnen et al., 2013; Mallarino et al., 2017). Moreover, this region is not highly conserved (in rodents), suggesting it may have evolved regulatory function only recently. This new regulatory element further supports the observation that Agouti regulation is highly modular (Linnen et al., 2013; Mallarino et al., 2017; Vrieling et al., 1994), which could, in turn, explain why Agouti expression may be the target of repeated evolutionary tinkering across vertebrates, for example, in rabbits (Jones et al., 2018), dogs (Bannasch et al., 2021), buffalo (Liang et al., 2021) and birds (Nadeau et al., 2008; Uy et al., 2016) - akin to other highly modular genes, such as Pax6 in vertebrates (Kammandel et al., 1999); Pitxl in stickleback fish (Chan et al., 2010; Thompson et al., 2018); Ebony in Drosophila (Signor et al., 2016); and Asip2b/Agrp2 in cichlid fishes (Kratochwil et al., 2018). 
This Agouti regulatory element likely contains causal mutation(s) that affect pigmentation. In total, there are 11 fixed differences between the light and dark Agouti alleles found in beach and mainland mice. While precisely which variant(s) are causal remains unclear, the three of these SNPs that are significantly associated with overall pigmentation (pPC1) in the polymorphic albifrons population represent the strongest candidates (Table S5). We also observe several complex indels and repetitive elements in the same region, which may themselves affect Agouti expression and drive an association signal in linked SNPs. While many of these variants disrupt predicted transcription factor binding sites identified in Mus (Table S4), such predictive approaches have poor specificity, and it is unclear if or when any of these sites may be active. And because this region is not well conserved even among rodents, results from gene-editing experiments in Mus, particularly ones that could result in subtle variation between mutants, may be challenging to interpret. However, surveying additional individuals in the admixed albifrons population may allow us to pinpoint the causal mutation(s) in the future. Similarly, the establishment of dermal cell lines that express Agouti, which are currently unavailable, containing the correct trans environment could allow us to test the effects of specific mutations - or combinations of mutations - via luciferase assays.

With a regulatory element identified, one can now more easily determine the source of this variation. In our survey of Agouti variation across both beach and mainland populations, we found the light Agouti allele is fixed in beach populations (see below), but also segregating or even fixed in some dark mainland populations. Beach mice are known to have very small populations (Oli et al., 2001; Mullen et al., 2009), thus the opportunity for a new adaptive mutation to arise is low (Domingues et al., 2012). Moreover, because the beach habitat is relatively young (8-10 kya; MacNeil, 1950) and colonization of that habitat relatively recent (Domingues et al., 2012), there has been only limited time for a new mutation to arise, and much less time for this mutation to spread to and across the mainland via migration. Thus, a more parsimonious scenario suggests that the light Agouti allele was selected from standing genetic variation existing in the mainland population(s), possibly at mutation-selection balance. This is consistent with results from $M c 1 r$, in which the age estimate for the emergence of the causal Mclr mutation predates the age of the beach habitat (Domingues et al., 2012). Interestingly, this scenario was predicted almost a century ago by Francis Sumner (1926) based on reports of light-colored mice occurring on the mainland near isolated beach habitats (Howell, 1920). Taken together, our data indicate that the large mainland populations are likely to have been the source of the light Agouti allele.

This evolutionary scenario then raises the question of how the light Agouti allele is maintained in mainland populations, where it may be deleterious. Indeed, previous field experiments demonstrated that models of light mice experienced higher rates of predation than dark models in a dark-soil mainland habitat (Vignieri et al., 2010). We discuss two possible, and non-mutually exclusive, explanations. First, many mainland mice that carry the light Agouti allele (even homozygotes) appear to have relatively dark coloration typical of a mainland mouse. In Peromyscus, Agouti is known to contain multiple mutations that affect pigmentation (Linnen et al., 2013) and to interact with other pigmentation genes (e.g., Steiner et al., 2007); therefore, it is possible that epistatic interactions between mutation(s) in the newly discovered regulatory element and other mutations in Agouti or elsewhere in the genome explain why, in some populations, the light Agouti allele has minimal effect on pigmentation (see Manceau et al., 2010), thus limiting its visibility to selection. Indeed, previous work in beach mice demonstrated a role for epistasis between Mc1r, Agouti and Corin (Steiner et al., 2007; Manceau et al., in review). Second, in some mainland populations, such as $P$. p. albifrons, soil coloration is not uniformly dark, but rather patchy, with sometimes large regions of surprisingly light, beach-like substrate. Such mainland areas have light sandy soil due to the geological history of the southeastern US, which has experienced successive episodes of glacial advance and retreat, depositing light sediments inland and forming sand-dune habitats that remain to this day (Lane, 1994). Thus, the light Agouti allele may, at least in some mainland populations, be beneficial, consistent with a signature of positive selection on the light allele in the albifrons population. However, the P. p. albifrons population also harbors dark Agouti alleles, possibly 
due to migration from surrounding dark mainland populations (Haldane 1948, Mullen and Hoekstra, 2008) or spatially variable selection in patchy habitats (Pfeifer et al., 2019). Additional sampling through the range of $P$. polionotus, including measurements of soil color, combined with whole-genome resequencing may shed further light on these two hypotheses to explain the prevalence of the light Agouti allele in mainland populations.

While the light Agouti allele is found at varying frequency in mainland populations, this allele is fixed in both Gulf and Atlantic coast beach mice. The distribution of the light allele is consistent with a scenario in which the same allele was independently selected in the two beach lineages from standing genetic variation. We note, however, that without specific information about the causal mutation(s), we cannot rule out the formal possibility that independent mutations with similar phenotypic effects evolved within the same small regulatory region. However, given that the Gulf and Atlantic clades are closely related and recently derived from similar mainland ancestors (Steiner et al., 2007), some may argue this was an ideal scenario for repeated selection on shared ancestral variation (e.g., Bolnick et al., 2018; Conte et al., 2012). Sharing the same Agouti light allele would provide a simple mechanistic explanation for why the Gulf and Atlantic Coast beach mice are so similar in coloration (see Hoekstra et al., 2006).

Together, these results suggest a scenario in which a cis-acting regulatory mutation(s) in Agouti likely evolved in the mainland and was independently selected in both the Gulf and Atlantic coast beach mice, contributing to their rapid, parallel evolution. This evolutionary history is in stark contrast with previous results for a second pigmentation gene Mclr (Hoekstra et al., 2006). In this latter case, it is a coding change (i.e., a single amino-acid mutation that reduces receptor signaling) that contributes to light coloration in beach mice. Also, this Mclr mutation is found in (some but not all) Gulf coast beach subspecies but is completely absent from Atlantic coast beach mice (Steiner et al., 2009), thereby not contributing to their parallel color adaptation. Thus, together, these two genes demonstrate how - even within a single species and associated with the same phenotype - evolution may take very different genetic paths to similar phenotypic ends.

\section{Acknowledgements}

We thank M. Omura of the Harvard Museum of Comparative Zoology (MCZ) for assistance in preparing and accessioning voucher specimens, N. Bedford for collecting P. p. leucocephalus specimens for whole genome sequencing, and E. Kingsley for providing P. m. nubiterrae samples, J. Weber and E. Delaney for assistance in the field. C. Hu designed the illustration in Fig. 2A. T. Capellini provided advice on the reporter assays and feedback on a draft of this manuscript together with S. He, C. Kratochwil and M. Manceau. AFK was supported by postdoctoral fellowships from the European Molecular Biology Organization (EMBO; ALTF 47-2018) and the German Science Foundation (DFG; KA 5308/1-1), JML from EMBO (ALTF 379-2011), the Human Frontiers Science Program (LT001086/2012), and the Belgian American Educational Foundation, and VSD from the Portuguese Foundation for Science and Technology. Fieldwork was supported by a MCZ Putnam Grant (to VSD and HEH), and lab work by the NIH (R35GM133758 to RM) and NSF (DEB-0919190 to HEH). HEH is an Investigator of the Howard Hughes Medical Institute.

\section{Author contributions}

VSD and HEH conducted the field collections. JML generated the genome assembly annotation, and VSD generated the sequence capture data. TBW, AFK, and JML generated whole genome resequencing data. TBW and AFK performed all additional genomic analyses. TBW and SM scored pigmentation traits. 
TBW and RM designed the reporter assays, and RM performed tissue sectioning. TBW, AFK, and HEH wrote the manuscript, with input from all authors.

\section{Materials and Methods}

\section{Specimen and tissue collection}

Over two expeditions, in the summer and winter of 2009, we collected 168 Peromyscus polionotus albifrons mice from a single population occupying habitat with patches of both light-colored sand and dark loam-clay soil in Lafayette Creek Wildlife Management Area of Walton County, Florida, approximately $25 \mathrm{~km}$ inland from the Gulf of Florida (Table S1). Mice were captured overnight using Sherman live traps. Following euthanasia, we sampled liver tissue from each individual and placed the tissue in $95 \%$ ethanol until they could be transferred to $-80^{\circ} \mathrm{C}$ for long-term storage. We also prepared standard museum skins and skeletons. Both tissue and specimens were then accessioned in Harvard University's Museum of Comparative Zoology (MCZ). In addition to P. p. albifrons, we included specimens from 10 distinct beach and mainland locations - representing eight additional polionotus subspecies - across the southeastern United States, as well as P. maniculatus nubiterrae from the northeastern US as an outgroup (Table S1). Tissues and voucher specimens are accessioned in the Harvard MCZ (Table S5).

\section{Measurement of pigment variation}

We measured 23 pigmentation traits on specimens prepared as flat skins using two approaches: (1) the distribution of pigmentation (e.g., tail-stripe length) or (2) the intensity of pigment (e.g., dorsal hue, brightness). These specific traits were chosen because they are known to vary among beach mouse populations (see Mullen et al., 2009; Steiner et al., 2007; 2009); we did not find any new body regions that showed measurable variation with the albifrons population. We first scored the extent of pigmentation for 14 body regions, including dorsal, flank, and ventrum pigmentation, rump shape and rump shadow, ankle shadow, tail stripe, ear base, eyebrows, cheek, whiskers, rostrum, and between the eyes (see Fig. 2A). A test set of 10 individuals were scored by two independent researchers, and the methods refined until their scores were identical. For the full dataset, each trait was scored by a single individual across all specimens to ensure consistency: two researchers scored traits with each scoring half the traits in all individuals. Second, to measure pigment intensity, we used a FLAME UV-VIS spectrometer with a pulsed xenon light source, a $400 \mu \mathrm{m}$ reflectance probe, and OceanView software (Ocean Optics) to measure five reflectance spectra from each of three body regions (dorsal stripe, flank, and ventrum). We used a custom $R$ script to obtain brightness, hue, and saturation values in the visible spectrum (400-700 nm) with $1 \mathrm{~nm}$ bin width, using a segment classification approach (Endler, 1990) with formulae as described for CLR v 1.05 (Montgomerie, 2008). For all traits, we took five measurements and then calculated the median value for each body region for each individual. In total, we measured these 23 traits on 168 P. p. albifrons specimens as well as representative individuals from the Gulf (P. $p$. leucocephalus, $\mathrm{n}=13)$, Atlantic ( $P . p$. niveiventris, $\mathrm{n}=15)$, and mainland (P. p. polionotus, $\mathrm{n}=17)$ populations.

\section{Trait correlations and phenotypic PCA}

To test for correlations among traits, we calculated pairwise trait correlations using the cor(., method="pearson", use="complete.obs") and cor.mtest() functions in base $R$, correcting for the number of pairwise tests to determine statistical significance (Bonferroni method). To account for trait correlations and to reduce the dimensionality of our dataset, we performed a principal component analysis (PCA) of all pigmentation traits using the FactoMineR (Lê et al., 2008) and factoextra (Kassambara and Mundt, 2020) $R$ libraries. More specifically, we first estimated the best number of dimensions for imputing 
missing data with estim_ncpPCA(., method.cv="Kfold"), imputed missing data based on the estimated number with imputePCA (., $n c p=5$ ) and then performed the PCA on the imputed dataset using the $P C A O$ function. Pairwise trait correlations and the phenotypic PCA were based on P. p. albifrons individuals only. To compare overall pigmentation (largely captured by phenotypic $\mathrm{PC} 1$ ) among populations, pigment scores for individuals from other populations were projected onto the albifrons principal component space post hoc using the predict() $R$ function.

\section{Genome sequencing and assembly}

DNA was extracted using standard laboratory procedures from the liver of one female (Peromyscus polionotus subgriseus; PO stock) obtained from our laboratory colony. By choosing a female individual, we have equal coverage for the autosomes and the $\mathrm{X}$ chromosome, but the $\mathrm{Y}$ chromosome is not part of the assembly. We prepared libraries with Illumina TruSeq DNA Sample Prep Kit v2 according to the manufacturer's instructions, and performed de novo sequencing on an Illumina HiSeq platform using a combination of short paired-end libraries and longer mate-pair libraries suitable for use with the ALLPATHS-LG genome assembler (Gnerre et al., 2011). All libraries were constructed and sequenced at the Broad Institute Sequencing Platform (Cambridge, MA, USA). In total, we generated $240.27 \mathrm{~Gb}$ of raw sequence data, representing a total physical coverage of $290 \mathrm{x}$, and assembled these reads using ALLPATHS-LG (version R48559).

We used ALLMAPS (Tang et al., 2015) in combination with five genetic maps based on interspecific crosses (RAD-based: Bendesky et al., 2017; Fisher et al., 2016; Kingsley 2015; Weber et al., 2013; genebased: Kenney-Hunt et al., 2014) to assemble the scaffolds into the pseudo-chromosomes. DNA sequences corresponding to 182 genes and RAD markers used to build the genetic maps were aligned against the genome using BLAT (Kent, 2002). Markers that could not be unambiguously mapped to a single location in the genome were filtered out. A total of 58,922 markers were included in the dataset. During a first iteration, ALLMAPS (Tang et al., 2015) revealed that a total of 66 scaffolds housed markers associated with more than one linkage group and were likely mis-assembled. These were subsequently split, and the position of the breakpoints determined based on the ALLMAPS predictions and the location of discordantly mapped reads. In most cases, these corresponded to assembly gaps. After correcting for these assembly errors, ALLMAPS was ran an additional time to generate the pseudochromosomes. Our final assembly includes 531 scaffolds, encompassing 2,575,648,500 bp (97.4\% of the total assembled sequence), distributed in 23 autosomes and the $\mathrm{X}$ chromosome. The orientation of 461 scaffolds corresponding to $2,566,039,849 \mathrm{bp}(97.0 \%$ of the total sequence) could be determined due to the presence of more than one marker. We assigned chromosome names based on previous reports from interspecific reciprocal whole chromosome painting, which have allowed to assign linkage groups with known genes to Peromyscus chromosomes (Kenney-Hunt et al., 2014, Brown et al., 2018). The chosen chromosome assignments reflect the standardized Peromyscus cytogenetic nomenclature (Greenbaum et al., 1994).

\section{Genome annotation}

We annotated repetitive elements using a combination of RepeatModeler (Smit and Hubley, 2008) and RepeatMasker (Smit et al., 2013) using Peromyscus- and rodent-specific repeat libraries. To annotate protein-coding genes, we used a recently developed annotation strategy making use of multiple genome alignments and an existing high-quality annotation set (Fiddes et al. 2018). While permitting the finding of newly discovered genes via ab initio gene modeling, this approach allows to identify orthology relationships readily and with high accuracy. We first aligned the oldfield mouse chromosome-level assembly to the assemblies of the laboratory mouse (Mus musculus; GRCm38), the rat (Rattus norvegicus; Rnor_6.0), the prairie vole (Microtus ochrogaster; MicOch1.0) and the prairie deer mouse (Peromyscus maniculatus; Pman2.1.3) using ProgressiveCactus (Paten et al. 2011a, 2011b). We reasoned that including more species that represent progressive level of evolutionary divergence would improve the accuracy of the ancestral sequence reconstruction process that takes place during the preparation of the 
whole-genome alignment. Using the Comparative Annotation Toolkit (CAT; Fiddes et al., 2018), we annotated the oldfield mouse genome using the genome of Mus musculus (GRCm38/mm10) and the highquality and well-curated GENCODE VM15 as the reference gene/transcript set, as well as extensive transcriptome sequencing datasets for $P$. polionotus corresponding to five tissues (brain, testis, hypothalamus, main olfactory epithelium and vomeronasal organ).as well as skin RNA-Seq data from the prairie deer mouse, $P$. maniculatus bairdii.

To obtain quantitative measures of the completeness of the genome assembly, we used BUSCO (Simão et al. 2015; version 3.0.2) with BLAST+ (version 2.2.28+), HMMER (version 3.1b2) and AUGUSTUS (version 3.3.2). We used human as species, which specifies the parameters used by AUGUSTUS, and the mammalia and euarchontoglires sets for our analyses.

\section{Population sequencing, variant calling, and genotype likelihoods}

For high coverage whole-genome sequencing (WGS) of representative beach (P. p. leucocephalus) and mainland (P. p. subgriseus) populations, we extracted DNA from $\sim 20 \mathrm{mg}$ of liver tissue and generated sequencing libraries using a PCR-free KAPA HTP kit. Following enzymatic fragmentation, we used size selection to enrich for a $450 \mathrm{bp}$ insert size and ligated Illumina adapters. We sequenced the resulting libraries using 150bp paired-end sequencing on an Illumina NovaSeq S4 flowcell to achieve 15-20X coverage.

For additional Gulf, Atlantic, and mainland populations, we used a sequence capture strategy aimed at sequencing both (1) putatively neutral loci and (2) the pigmentation genes Agouti and Mclr. Specifically, we targeted $\sim 50001.5 \mathrm{~kb}$ non-coding regions randomly distributed across the genome as well as $190 \mathrm{~kb}$ and $150 \mathrm{~kb}$ regions flanking the Agouti and Mclr loci, respectively (see Domingues et al. 2012 for capture array design details; Kingsley et al., 2009 for Agouti and Mclr sequencing details). This strategy was applied to five Gulf beach mouse subspecies (P. p. ammobates, P. p. allophrys, P. p. trisyllepsis, $P$. p. peninsularis, $P$. p. leucocephalus), three mainland subspecies ( $P$. p. polionotus, $P$. p . albifrons, three populations of $P$. p. subgriseus) and one Atlantic beach subspecies ( $P$. p. niveiventris) (see Table S1). The availability of both high-quality WGS and sequence capture data for the $P$. p. leucocephalus and $P$. $p$. subgriseus subspecies allowed us to verify that the sequence capture loci accurately represented each population's genetic diversity.

For both WGS and sequence capture data, we converted raw fastq files to unmapped bam files using FastqToSam (Picard toolkit, 2019) and then marked Illumina adapters using MarkIlluminaAdapters (Picard). Using SamToFastq (Picard), we created interleaved fastq files and clipped adapter sequences. We mapped sequencing reads to the $P$. polionotus subgriseus reference genome (see above) using bwamem (Li and Durbin, 2009), with - $\mathrm{p}$ to indicate interleaved paired-end fastq input, and -M to mark short split hits as secondary for compatibility with Picard. We then used MergeBamAlignment (Picard) to merge mapped and unmapped bam files to preserve read group information and sequencing duplicates using MarkDuplicates (Picard), with OPTICAL_DUPLICATE_PIXEL_DISTANCE $=2500$ to account for artifacts generated from the patterned flowcell found in the NovaSeq S4.

We then called variants separately for the WGS and sequence-capture datasets to reduce processing time, as they vary significantly in both coverage and sample number. However, the following variant calling and filtering steps were applied equally to both data types. To begin, we used HaplotypeCaller (GATK 3.8; Poplin et al., 2018) on the aligned bam files with the default heterozygosity prior (-hets = 0.005) and-ERC GVCF to produce per-sample gVCFs. For the X chromosome, we specified a prior input ploidy based on a comparison of coverage with the autosomes using samtools (v. 1.10) depth (Li et al., 2009). Next, for the WGS data, we generated variant + invariant cohort-level vcfs for each chromosome using GenotypeGVCFs (GATK 3.8) with "--max-alternate--alleles 4 -all-sites". For the sequence capture data, the "-allsites" parameter was removed and only variants were reported. These raw, cohort level vcfs were split into indels and SNPs with SplitVcfs (Picard) and invariant sites with SelectVariants (GATK 3.8). We performed filtering on each set independently, excluding SNPs with QD $<2.0, \mathrm{FS}>10.0, \mathrm{MQ}<40.0, \mathrm{MQRankSum}<-12.5$, ReadPosRankSum $<-8.0$ or SOR $>3.0$ and 
excluding INDELs with QD $<2.0$, FS $>200.0$, ReadPosRankSum $<-20.0$, SOR $>3.0$. We also retained invariant sites with QUAL $\geq 20$ using bcftools 1.11-95 (Li, 2011). These filtering parameters were based on a combination of GATK recommendations for datasets without truth/training sets, and visual inspection of the distributions for each metric. We also set individual genotype calls to missing if the read depth at a given site was less than five. Finally, we combined the sequence capture dataset with the WGS dataset using vcf-merge (vcftools 0.1.15; Danecek et al., 2011).

\section{Estimation of population structure}

To test for population structure, we ran a genetic principal components analysis (gPCA) using PCAangsd, which is specialized for use with low-coverage, high-throughput sequencing data (Meisner and Albrechtsen, 2018). We used beagle genotype probability files for all sequence-capture loci as input and ran the program with default parameters. Using the output covariance matrix, we calculated eigenvalues and eigenvectors with the base $\mathrm{R}$ function eigen. We estimated population differentiation (Fst) for all pairwise population comparisons using the program ANGSD (Korneliussen et al., 2014). We first calculated the two-population site frequency spectra (2DSFS) using the SAF files generated by $A N G S D$, running realSFS with default parameters. We then generated the Fst index for each population pair with realSFS fst index, supplying each population's SAF index and the 2DSFS with default parameters. The resulting Fst index file allowed us to estimate global Fst as well as Fst in sliding windows, using realSFS fst stats and realSFS fst stats 2 , respectively.

\section{Estimation of population relationships}

To estimate the relationships among the sampled subspecies, we constructed a population-level tree using a modified version of $S N A P P$, a multispecies coalescent-based tool that uses biallelic markers as input (Bouckaert et al., 2019; Bryant et al., 2012; Stange et al., 2018). Our input data consisted of genome-wide putatively neutral variants sampled in both the sequence-capture and whole-genome datasets (i.e., excluding the Agouti and Mclr regions). Briefly, we chose the two highest-coverage individuals representing each population, then retained biallelic SNPs with minor allele frequency greater than 0.05 , excluded variants that violated Hardy-Weinberg equilibrium ( $\mathrm{p}$-value $<0.001$ ) in four or more populations, and thinned the remaining variants so that none were within $100 \mathrm{bp}$ of each other. The remaining variants were reformatted as a phylip file and converted to the xml format required by $S N A P P / B E A S T$ using the script snapp_prep.rb

(https://raw.githubusercontent.com/mmatschiner/snapp_prep/master/snapp_prep.rb). To specify a starting tree constraint (-s), we ran $R A x M L$ (Stamatakis, 2014) with ascertainment bias correction (--asccorr=lewis) on a reduced dataset containing the highest coverage representative of each subspecies to obtain a maximum likelihood phylogeny. We also specified a node constraint (-c) that the crown divergence of all subspecies, excluding $P$. maniculatus nubiterrae (outgroup), should approximate a normal distribution mean of 8.9 kya and a standard deviation of 1.5 kya. These values were taken from $S M C++$ estimates of the divergence time between mainland (P. p. subgriseus) and beach ( $P . p$. leucocephalus) subspecies, assuming a generation time of four months (i.e., 3 generations/year; see 'Demographic Inference' below). Finally, we sampled 1000 random variants from the remaining dataset to speed up run times and specified 1 million MCMC iterations. For quality control, we confirmed thorough mixing in the run using Tracer v1.7.1 (Rambaut et al., 2018) and visually inspected the trees using DensiTree (Bouckaert, 2010). A consensus tree was generated with TreeAnnotator (Bouckaert et al., 2019), using a 10\% burn-in and reporting mean node heights.

\section{Demographic inference}

The whole-genome, high-density sequencing coverage for one mainland (P.p. subgriseus) and one beach ( $P$. p. leucocephalus) subspecies allowed us to infer demographic histories with high resolution. Specifically, we used the program $S M C++$ (Terhorst et al., 2016) to estimate population divergence times 
and parameterize population size changes in additional populations. To mask low-quality regions, we followed the SNPable protocol (http://h3lh3.users.sourceforge.net/snpable.shtml) to identify regions in the assembly with poor mappability, using a k-mer size of $150 \mathrm{bp}$. SNPs that violated Hardy-Weinberg equilibrium $(\mathrm{p}<0.01)$ and had low population coverage $(<80 \%$ samples genotyped) were also excluded.

We then used the $v c f 2 s m c$ command to create the per-population SMC input files, supplying mappability, missingness, and Hardy-Weinberg masks to exclude low quality regions in the dataset. The 'distinguished individual' (DI), a key feature of $S M C++$, was specified as the highest coverage sample for each population. We generated two-population input files using the same command and input files, but with no specified DI (not applicable to multi-population analysis). For single-population inference, we used $c v$ with the following parameters: '--folds 4 --timepoints $1 \mathrm{e} 35 \mathrm{e} 7$--Nmax $1 \mathrm{e} 8$-spline cubic' and a germline mutation rate of 5.3e-9 (Uchimura et al., 2015). We also ran estimate, an earlier version of $s m c++c v$, with identical parameters for downstream compatibility with population-split inference. We then provided single-population demographic models (as obtained by smc ++ estimate) and twopopulation input files to split to estimate the timing of the mainland (subgriseus) and beach (leucocephalus) split. To obtain confidence intervals for all the estimates described above, we used a custom script to resample $10 \mathrm{Mb}$ stretches of the genome in the SMC input files, thus generating 20 bootstrap replicates per estimate. The above pipeline was rerun with identical parameters on these replicates, and $95 \%$ confidence intervals were calculated as mean $+-2 *$ standard error.

\section{Genome-wide association mapping}

Genotype-phenotype associations were determined using the mixed-model approach implemented in EMMAX (beta-07Mar2010), accounting for population structure / relatedness by incorporating a BaldingNichols kinship matrix as a random effect (Kang et al., 2010). We set the statistical significance threshold at $\mathrm{p}<0.05$ after correcting (Bonferroni method) for the number of effective independent tests. We obtained the latter using Genetic Type I error calculator (GEC) v0.2 (Li et al., 2012). We excluded samples with more than $50 \%$ missing genotypes from these analyses, leaving $\mathrm{N}=152$ samples. We used both biallelic SNPs and indels for association mapping, but excluded markers with $>50 \%$ missing data, a minor allele frequency $<0.05$, or deviating from Hardy-Weinberg equilibrium $(\mathrm{p}<0.001)$. We generated Manhattan plots and QQ plots using the qqman (Turner, 2018) and snpStats (Clayton, 2021) R libraries, respectively. Using plink (v1.90b6.15), we calculated pairwise linkage disequilibrium $\left(\mathrm{r}^{2}\right)$ among SNPs in the focal region (flags: --chr chr4 --from-bp 9820301 --to-bp 9870301 --r2 --ld-window-r2 0 --ld-window 1000). Next, we estimated the proportion of variance explained (PVE) for a given SNP (assuming HardyWeinberg equilibrium) using genotype-phenotype regressions.

\section{Sequence conservation}

To evaluate the nucleotide sequence conservation level of the Agouti locus in P.polionotus, including the candidate regulatory region, we downloaded all available orthologous rodent Agouti sequences from NCBI (accessed pt. 7, 2020) using esearch (-db gene -query "ortholog_gene_434[group] AND rodents[orgn]") in combination with esummary and xtract of the entrez direct e-utilities. Next, we manually added $15 \mathrm{~kb}$ to each of the start and end coordinates (or the maximum number of bp if hitting a scaffold end) using a custom awk script and retrieved the corresponding nucleotide sequences with efetch. The sequence of Nannospalax galili was removed due to a lack of available flanking sequence. Finally, we determined sequence conservation between $P$. polionotus and the remaining 26 rodent species using mVISTA (Frazer et al., 2004).

\section{Regulatory database queries}

To determine if the candidate regulatory region of Agouti contains any known regulatory elements or transcription factor binding sites, we downloaded both phastCons60way conserved elements and ORegAnno regulatory elements from the UCSC genome browser in Mus musculus mm10 coordinates 
(http:/hgdownload.cse.ucsc.edu/goldenpath/mm10/database/). Elements from each database were converted to $P$. polionotus genomic coordinates using UCSC's liftOver utility (Kent et al., 2002) and a custom chain file, with the parameters '-multiple -minMatch $=0.70$ '.

We obtained ENSEMBL regulatory features using the $R$ package biomaRt (Durinck et al., 2009, 2005). The $\mathrm{mm} 39$ regulatory feature dataset was retrieved with the function useDataset(), with the parameters 'dataset="mmusculus_regulatory_feature", mart= "ENSEMBL_MART_FUNCGEN"', and getBM() was used to retrieve entries from the broader Agouti region using the extended Agouti coordinates $(2: 154785921: 155055915)$ for the mm39 assembly. We directly converted coordinates in $\mathrm{mm} 39$ to $\mathrm{mm} 10$ assembly coordinates using liftOver with default parameters and the UCSC mm39toMm10 chain file (https://hgdownload.soe.ucsc.edu/goldenPath/mm39/liftOver/mm39ToMm10.over.chain.gz), then converted mm10 coordinates to $P$. polionotus coordinates using the same approach described above.

\section{LacZ reporter assay}

To determine if the candidate region was capable of regulatory activity, we assessed whether it could drive expression of the lacZ reporter gene in the skin of developing mouse embryos (strain: FVB/NJ). To identify the most appropriate sequence length for this experiment, we specified boundaries that encompassed the three pPC1-significant SNPs, the unique local topology regions identified by Saguaro (see Methods: Local tree inference with Saguaro) and the tract of relatively high sequence conservation at the 3' end of the association \& Saguaro regions, resulting in a total sequence length of $2.6 \mathrm{~kb}$ (Fig. 4B). While lac $Z$ experiments are particularly useful for verifying that a regulatory locus is active, comparisons between alleles of the same locus (e.g., light and dark alleles) can be challenging due to the noise associated with random genomic integration of the construct. Therefore, presented with two alternative haplotypes in this region - "light" and "dark" - we decided to use the light haplotype for these experiments, under the assumption that the light allele was less likely to contain mutations reducing element activity (i.e., high Agouti expression is generally associated with light pigmentation).

We used the lacZ expression vector, hsp68lacZ (gift from T. Capellini, Addgene \#37843). The light haplotype sequence file and hsp68lacZ vector were provided to Taconic Biosciences (NY, USA) who synthesized and cloned the sequence upstream of the hsp68 minimal promoter, followed by pronuclear microinjection, collection of E14.5 embryos, genotyping, and lacZ staining. Stained embryos were shipped to our laboratory, where they were photographed, embedded in OCT, cryosectioned, and imaged.

\section{Transcription factor binding site prediction}

To determine if variation in the regulatory element could be modifying relevant transcription factor (TF) binding sites, we examined motif differences at variant positions across the region. Specifically, we obtained all polymorphic sites in the regulatory element (chr4:9,844,852 bp - 9,847,500 bp) with minor allele frequency $(\mathrm{MAF})>0.05$ in the $P$. p. albifrons population. We extracted the region $15 \mathrm{bp}$ upstream and downstream of each variant ( $\sim 30$ bp sequence) and used $v c f$-consensus (vcftools 0.1 .15$)$ to create an alternate sequence incorporating the variant. For each reference and alternate sequence, we used CiiiDER v.0.9 (Gearing et al., 2019) to predict TF binding sites, providing the database of 251 Mus musculus CORE TF position weight matrices available on JASPAR (downloaded 10-20-21; Fornes et al., 2020).

\section{Haplotype homozygosity tests}

To test for evidence of non-neutral evolution in patterns of nucleotide variation, we calculated haplotype statistics. We first ran fastPHASE to create phased variant calls (Scheet and Stephens, 2006). We converted the input vcf for all individual genotypes at Agouti, Mclr, and the sequence-capture loci to the fastPHASE format with vcf2fastPHASE.pl (https://github.com/lstevison/vcf-conversion-tools), then ran fastPHASE with the following parameters: -T20 -H50 -F. We next converted the phased output back to the vcf format with fastPHASE2VCF.pl. 
Using the $R$ package $R E H H$, we ran a series haplotype-based tests to scan for signatures of positive selection on the light and dark haplotypes (Gautier et al., 2017). For each population, we converted vcfs to an REHH-compatible file with a custom script (hap2rehh.py), using the P. polionotus subgriseus reference genome to polarize alleles. We then converted these files to haplohh objects with data2haplohh, then computed Extended haplotype homozygosity (EHH) statistics with scan_hh, with the parameters 'discard_integration_at_border=FALSE, maxgap $=2000$ ' to accommodate the sequence-capture dataset. We then ran ihh2ihs to calculate integrated haplotypes scores (IHS), using a minor allele frequency (MAF) filter of 0.05 and default allele frequency bin sizes of 0.025 .

\section{Local tree inference with Saguaro}

As a complementary approach to test for evidence of selection within Agouti, we used the Hidden Markov Model (HMM)-based software Saguaro to build local phylogenies from sequence data (Zamani et al., 2013). As input, we used variant calls from the sequence-capture dataset and the Agouti and Mclr extended loci, and filtered out variants with $\mathrm{MAF}<0.025$. To reduce computational complexity and help with downstream interpretation, we reduced the sample size to include only the two highest-coverage representatives of each population. In the case of albifrons, we included two individuals homozygous for the "dark" allele and two for the 'light' allele (as determined by their genotype at SNP chr4:9,845,301bp). We then used VCF2HMMFeature to transform the variant calls to a Saguaro-compatible input format. We ran Saguaro for 15 iterations with default parameters. We transformed the resulting topologies to phylip files with Saguaro2Phylip and used a custom script to parse the LocalTrees.out file to obtain HMM transitions across the dataset. 


\section{References}

Barrett RDH, Schluter D. 2008. Adaptation from standing genetic variation. Trends Ecol Evol 23:38-44. doi:10.1016/j.tree.2007.09.008

Barsh GS. 1996. The genetics of pigmentation: from fancy genes to complex traits. Trends Genet 12:299305. doi:10.1016/0168-9525(96)10031-7

Bannasch DL, Kaelin CB, Letko A, Loechel R, Hug P, Jagannathan V, Henkel J, Roosje P, Hytönen MK, Lohi H, Arumilli M, Minor KM, Mickelson JR, Drögemüller C, Barsh GS, Leeb T. 2021. Dog colour patterns explained by modular promoters of ancient canid origin. Nat Ecol Evol 5:14151423. doi:10.1038/s41559-021-01524-X

Bendesky A, Kwon Y, Lassance J, Lewarch CL, Yao S, Peterson BK. 2017. The genetic basis of parental care evolution in monogamous mice. Nature 544:434-439. doi:10.1038/nature22074

Bolnick DI, Barrett RDH, Oke KB, Rennison DJ, Stuart YE. 2018. (Non)Parallel evolution. Annu Rev Ecol Evol Syst 49:303-330. doi:10.1146/annurev-ecolsys-110617-062240

Bouckaert R, Vaughan TG, Barido-Sottani J, Duchêne S, Fourment M, Gavryushkina A, Heled J, Jones G, Kühnert D, Maio ND, Matschiner M, Mendes FK, Müller NF, Ogilvie HA, Plessis L du, Popinga A, Rambaut A, Rasmussen D, Siveroni I, Suchard MA, Wu C-H, Xie D, Zhang C, Stadler T, Drummond AJ. 2019. BEAST 2.5: An advanced software platform for Bayesian evolutionary analysis. PLoS Comput Biol 15:e1006650. doi:10.1371/journal.pcbi.1006650

Bouckaert RR. 2010. DensiTree: making sense of sets of phylogenetic trees. Bioinformatics 26:13721373. doi:10.1093/bioinformatics/btq110

Brown J, Crivello J, O’Neill RJ. 2018. An updated genetic map of Peromyscus with chromosomal assignment of linkage groups. Mamm Genome 29:344-352. doi:10.1007/s00335-018-9754-7

Bryant D, Bouckaert R, Felsenstein J, Rosenberg NA, RoyChoudhury A. 2012. Inferring species trees directly from biallelic genetic markers: bypassing gene trees in a full coalescent analysis. $\mathrm{Mol}$ Biol Evol 29:1917-1932. doi:10.1093/molbev/mss086

Caro T, Mallarino R. 2019. Coloration in mammals. Trends Ecol Evol 35:357-366. doi:10.1016/j.tree.2019.12.008

Carroll SB. 2008. Evo-devo and an expanding evolutionary synthesis: a genetic theory of morphological evolution. Cell 134:25-36. doi:10.1016/j.cell.2008.06.030

Chan YF, Marks ME, Jones FC, Villarreal G, Shapiro MD, Brady SD, Southwick AM, Absher DM, Grimwood J, Schmutz J, Myers RM, Petrov D, Jónsson B, Schluter D, Bell MA, Kingsley DM. 2010. Adaptive evolution of pelvic reduction in sticklebacks by recurrent deletion of a Pitxl enhancer. Science 327:302-305. doi:10.1126/science.1182213

Clayton D. 2021. snpStats: SnpMatrix and XSnpMatrix classes and methods. R package version 1.44.0

Conte GL, Arnegard ME, Peichel CL, Schluter D. 2012. The probability of genetic parallelism and convergence in natural populations. Proc $R$ Soc B 279:5039-5047. doi:10.1098/rspb.2012.2146

Danecek P, Auton A, Abecasis G, Albers CA, Banks E, DePristo MA, Handsaker RE, Lunter G, Marth GT, Sherry ST, McVean G, Durbin R, 1000 Genomes Project Analysis Group. 2011. The variant call format and VCFtools. Bioinformatics 27:2156-2158. doi:10.1093/bioinformatics/btr330

Domingues VS, Poh Y, Peterson BK, Pennings PS, Jensen JD, Hoekstra HE. 2012. Evidence of adaptation from ancestral variation in young populations of beach mice. Evolution 66:3209-3223. doi:10.1111/j.1558-5646.2012.01669.x

Durinck S, Moreau Y, Kasprzyk A, Davis S, De Moor B, Brazma A, Huber W. 2005. BioMart and Bioconductor: a powerful link between biological databases and microarray data analysis. Bioinformatics 21:3439-3440. doi:10.1093/bioinformatics/bti525

Durinck S, Spellman PT, Birney E, Huber W. 2009. Mapping identifiers for the integration of genomic datasets with the R/Bioconductor package biomaRt. Nat Protoc 4:1184-1191. doi:10.1038/nprot.2009.97 
Endler JA. 1990. On the measurement and classification of colour in studies of animal colour patterns. Biol J Linn Soc 41:315-352. doi:10.1111/j.1095-8312.1990.tb00839.x

Enshell-seijffers D, Lindon C, Morgan BA. 2008. The serine protease Corin is a novel modifier of the agouti pathway. Development 225:217-225. doi:10.1242/dev.011031

Fiddes IT, Armstrong J, Diekhans M, Nachtweide S, Kronenberg ZN, Underwood JG, Gordon D, Earl D, Keane T, Eichler EE, Haussler D, Stanke M, Paten B. 2018. Comparative Annotation Toolkit (CAT) - simultaneous clade and personal genome annotation. Genome Res 28:1029-1038. doi:10.1101/gr.233460.117

Fisher HS, Jacobs-Palmer E, Lassance J-M, Hoekstra HE. 2016. The genetic basis and fitness consequences of sperm midpiece size in deer mice. Nat Commun 7:13652. doi:10.1038/ncomms 13652

Fornes O, Castro-Mondragon JA, Khan A, van der Lee R, Zhang X, Richmond PA, Modi BP, Correard S, Gheorghe M, Baranašić D, Santana-Garcia W, Tan G, Chèneby J, Ballester B, Parcy F, Sandelin A, Lenhard B, Wasserman WW, Mathelier A. 2020. JASPAR 2020: update of the open-access database of transcription factor binding profiles. Nucleic Acids Res 48:D87-D92. doi:10.1093/nar/gkz1001

Frazer KA, Pachter L, Poliakov A, Rubin EM, Dubchak I. 2004. VISTA: computational tools for comparative genomics. Nucleic Acids Res 32:W273-W279. doi:10.1093/nar/gkh458

Gautier M, Klassmann A, Vitalis R. 2017. REHH 2.0: a reimplementation of the R package REHH to detect positive selection from haplotype structure. Mol Ecol Resour 17:78-90. doi:10.1111/17550998.12634

Gearing LJ, Cumming HE, Chapman R, Finkel AM, Woodhouse IB, Luu K, Gould JA, Forster SC, Hertzog PJ. 2019. CiiiDER: A tool for predicting and analysing transcription factor binding sites. PLoS ONE 14:e0215495. doi:10.1371/journal.pone.0215495

Gnerre S, MacCallum I, Przybylski D, Ribeiro FJ, Burton JN, Walker BJ, Sharpe T, Hall G, Shea TP, Sykes S, Berlin AM, Aird D, Costello M, Daza R, Williams L, Nicol R, Gnirke A, Nusbaum C, Lander ES, Jaffe DB. 2011. High-quality draft assemblies of mammalian genomes from massively parallel sequence data. Proc Natl Acad Sci 108:1513-1518. doi:10.1073/pnas.1017351108

Greenbaum IF, Gunn SJ, Smith SA, McAllister BF, Hale DW, Baker RJ, Engstrom MD, Hamilton MJ, Modi WS, Robbins LW, Rogers DS, Ward OG, Dawson WD, Elder FFB, Lee MR, Pathak S, F. B. Stangl J. 1994. Cytogenetic nomenclature of deer mice, Peromyscus (Rodentia): revision and review of the standardized karyotype. Cytogenet Genome Res 66:181-195. doi: $10.1159 / 000133696$

Haldane JBS. 1948. The theory of a cline. J Genet 48:277-284. doi:10.1007/BF02986626

Hoballah ME, Gübitz T, Stuurman J, Broger L, Barone M, Mandel T, Dell'Olivo A, Arnold M, Kuhlemeier C. 2007. Single gene-mediated shift in pollinator attraction in Petunia. Plant Cell 19:779-790. doi:10.1105/tpc.106.048694

Hoekstra HE, Coyne JA. 2007. The locus of evolution: evo devo and the genetics of adaptation. Evolution 61:995-1016. doi:10.1111/j.1558-5646.2007.00105.x

Hoekstra HE, Hirschmann RJ, Bundey RA, Insel PA, Crossland JP. 2006. A single amino acid mutation contributes to adaptive beach mouse color pattern. Science 313:101-105. doi:10.1126/science.1126121

Howell AH. 1920. Description of a new species of beach mouse from Florida. J Mammal 1:237-240. doi: $10.2307 / 1373248$

Jones MR, Mills LS, Alves PC, Callahan CM, Alves JM, Lafferty DJR, Jiggins FM, Jensen JD, MeloFerreira J, Good JM. 2018. Adaptive introgression underlies polymorphic seasonal camouflage in snowshoe hares. Science 360:1355-1358. doi:10.1126/science.aar5273 
Kalkvik HM, Stout JI, Hoffman EA, Parkinson CL. 2018. Colonization and divergence: phylogeography and population genetics of the Atlantic coast beach mice. System Biodivers 16:757-773. doi:10.1080/14772000.2018.1486339

Kammandel B, Chowdhury K, Stoykova A, Aparicio S, Brenner S, Gruss P. 1999. Distinct cis-essential modules direct the time-space pattern of the Pax6 gene activity. Dev Biol 205:79-97. doi:10.1006/dbio.1998.9128

Kang HM, Sul JH, Service SK, Zaitlen NA, Kong S, Freimer NB, Sabatti C, Eskin E. 2010. Variance component model to account for sample structure in genome-wide association studies. Nat Genet 42:348-354. doi:10.1038/ng.548

Kassambara A, Mundt F. 2020. factoextra: Extract and visualize the results of multivariate data analyses. $\mathrm{R}$ package version 1.0.7

Kenney-Hunt J, Lewandowski A, Glenn TC, Glenn JL, Tsyusko OV, O’Neill RJ, Brown J, Ramsdell CM, Nguyen Q, Phan T, Shorter KR, Dewey MJ, Szalai G, Vrana PB, Felder MR. 2014. A genetic map of Peromyscus with chromosomal assignment of linkage groups (a Peromyscus genetic map). Mamm Genome 25:160-179. doi:10.1007/s00335-014-9500-8

Kent WJ, Sugnet CW, Furey TS, Roskin KM, Pringle TH, Zahler AM, Haussler D. 2002. The Human Genome Browser at UCSC. Genome Res 12:996-1006. doi:10.1101/gr.229102

Kingsley EP, Manceau M, Wiley CD, Hoekstra HE. 2009. Melanism in Peromyscus is caused by independent mutations in Agouti. PLoS ONE 4:1-9. doi:10.1371/journal.pone.0006435

Kingsley EP. 2015. Adaptation in the forest deer mouse: evolution, genetics, and development. Harvard University, Ph.D. dissertation.

Korneliussen TS, Albrechtsen A, Nielsen R. 2014. ANGSD: Analysis of next generation sequencing data. BMC Bioinform 15:356-356. doi:10.1186/s12859-014-0356-4

Kowalko JE, Rohner N, Linden T a, Rompani SB, Warren WC, Borowsky R, Tabin CJ, Jeffery WR, Yoshizawa M. 2013. Convergence in feeding posture occurs through different genetic loci in independently evolved cave populations of Astyanax mexicanus. Proc Natl Acad Sci 110:169338. doi:10.1073/pnas.1317192110

Kratochwil CF, Liang Y, Gerwin J, Woltering JM, Urban S, Henning F, Machado-Schiaffino G, Hulsey CD, Meyer A. 2018. Agouti-related peptide 2 facilitates convergent evolution of stripe patterns across cichlid fish radiations. Science 362:457-460. doi:10.1126/science.aao6809

Lane E. 1994. Florida's geological history and geological resources. Fla Geol Surv Spec Pub 35:1-64.

Lê S, Josse J, Husson F. 2008. FactoMineR: An R package for multivariate analysis. J Stat Softw 25:118. doi:10.18637/jss.v025.i01

Lewis JJ, Geltman RC, Pollak PC, Rondem KE, Belleghem SMV, Hubisz MJ, Munn PR, Zhang L, Benson C, Mazo-Vargas A, Danko CG, Counterman BA, Papa R, Reed RD. 2019. Parallel evolution of ancient, pleiotropic enhancers underlies butterfly wing pattern mimicry. Proc Natl Acad Sci 116:24174-24183. doi:10.1073/pnas.1907068116

Liang D, Zhao P, Si J, Fang L, Pairo-Castineira E, Hu X, Xu Q, Hou Y, Gong Y, Liang Z, Tian B, Mao H, Yindee M, Faruque MO, Kongvongxay S, Khamphoumee S, Liu GE, Wu D-D, Barker JSF, Han J, Zhang Y. 2021. Genomic analysis revealed a convergent evolution of LINE-1 in coat color: a case study in water buffaloes (Bubalus bubalis). Mol Biol Evol 38:1122-1136. doi: $10.1093 / \mathrm{molbev} / \mathrm{msaa} 279$

Li H. 2011. A statistical framework for SNP calling, mutation discovery, association mapping and population genetical parameter estimation from sequencing data. Bioinformatics 27:2987-2993. doi:10.1093/bioinformatics/btr509

Li H, Handsaker B, Wysoker A, Fennell T, Ruan J, Homer N, Marth G, Abecasis G, Durbin R, 1000 Genome Project Data Processing Subgroup. 2009. The sequence alignment/map format and SAMtools. Bioinformatics 25:2078-2079. doi:10.1093/bioinformatics/btp352

Li H, Durbin R. 2009. Fast and accurate short read alignment with Burrows-Wheeler transform. Bioinformatics 25:1754-1760. doi:10.1093/bioinformatics/btp324 
Li M-X, Yeung JMY, Cherny SS, Sham PC. 2012. Evaluating the effective numbers of independent tests and significant p-value thresholds in commercial genotyping arrays and public imputation reference datasets. Hum Genet 131:747-756. doi:10.1007/s00439-011-1118-2

Linnen CR, Kingsley EP, Jensen JD, Hoekstra HE. 2009. On the origin and spread of an adaptive allele in deer mice. Science 325:1095-1098. doi:10.1126/science.1175826

Linnen CR, Poh Y-P, Peterson BK, Barrett RDH, Larson JG, Jensen JD, Hoekstra HE. 2013. Adaptive evolution of multiple traits through multiple mutations at a single gene. Science 339:1312-1316. doi:10.1126/science. 1233213

MacNeil FS. 1950. Pleistocene shore lines in Florida and Georgia. Geol Surv Prof Pap 221-F:95-107. doi:10.3133/pp221F

Mallarino R, Linden TA, Linnen CR, Hoekstra HE. 2017. The role of isoforms in the evolution of cryptic coloration in Peromyscus mice. Mol Ecol 26:245-258. doi:10.1111/mec.13663

Manceau M, Domingues VS, Linnen CR, Rosenblum EB, Hoekstra HE. 2010. Convergence in pigmentation at multiple levels: mutations, genes and function. Phil Trans $R$ Soc B 365:24392450. doi:10.1098/rstb.2010.0104

Manceau M, Domingues VS, Mallarino R. 2011. The developmental role of Agouti in color pattern evolution. Science 331:1062-1065. doi:10.1126/science.1200684

Manceau M, Jacobs-Palmer E, Mallarino R, Domingues VS, Hoekstra HE. Interacting pigment genes establish adaptive color patterns in Peromyscus. Submitted.

Martin A, Orgogozo V. 2013. The loci of repeated evolution: A catalog of genetic hotspots of phenotypic variation. Evolution 67:1235-1250. doi:10.1111/evo.12081

Meisner J, Albrechtsen A. 2018. Inferring population structure and admixture proportions in low-depth NGS data. Genetics 210:719-731. doi:10.1534/genetics.118.301336

Montgomerie R. 2008. CLR. Kingston, Canada: Queen's University.

Mullen LM, Hoekstra HE. 2008. Natural selection along an environmental gradient: A classic cline in mouse pigmentation. Evolution 62:1555-1570. doi:10.1111/j.1558-5646.2008.00425.x

Mullen LM, Vignieri SN, Gore JA, Hoekstra HE. 2009. Adaptive basis of geographic variation: genetic, phenotypic and environmental differences among beach mouse populations. Proc Royal Soc B 276:3809-3818. doi:10.1098/rspb.2009.1146

Nadeau NJ, Minvielle F, Ito S, Inoue-Murayama M, Gourichon D, Follett SA, Burke T, Mundy NI. 2008. Characterization of Japanese Quail yellow as a genomic deletion upstream of the avian homolog of the mammalian ASIP (agouti) gene. Genetics 178:777-786. doi:10.1534/genetics.107.077073

Oli MK, Holler NR, Wooten MC. 2001. Viability analysis of endangered Gulf Coast beach mice (Peromyscus polionotus) populations. Biol Conserv 97:107-118. doi:10.1016/S00063207(00)00104-X

Ollmann MM, Lamoreux ML, Wilson BD, Barsh GS. 1998. Interaction of Agouti protein with the melanocortin 1 receptor in vitro and in vivo. Genes Dev 12:316-330. doi:10.1101/gad.12.3.316

Oziolor EM, Reid NM, Yair S, Lee KM, Verploeg SG, Bruns PC, Shaw JR, Whitehead A, Matson CW. 2019. Adaptive introgression enables evolutionary rescue from extreme environmental pollution. Science 126:455-457. doi:10.1126/science.aav4155

Pai AA, Pritchard JK, Gilad Y. 2015. The genetic and mechanistic basis for variation in gene regulation. PLoS Genet 11:e1004857. doi:10.1371/journal.pgen.1004857

Paten B, Earl D, Nguyen N, Diekhans M, Zerbino D, Haussler D. 2011a. Cactus: Algorithms for genome multiple sequence alignment. Genome Res 21:1512-1528. doi:10.1101/gr.123356.111

Paten B, Diekhans M, Earl D, St John J, Ma J, Suh B, Haussler D. 2011b. Cactus graphs for genome comparisons. J Comput Biol 18:469-481. doi:10.1089/cmb.2010.0252

Pfeifer SP, Laurent S, Sousa VC, Linnen CR, Foll M, Excoffier L, Hoekstra HE, Jensen JD. 2018. The evolutionary history of Nebraska deer mice: local adaptation in the face of strong gene flow. Mol Biol Evol 35:792-806. doi:10.1093/molbev/msy004

Picard toolkit. 2019. Broad Institute, Github Repository. 
Poplin R, Ruano-Rubio V, DePristo MA, Fennell TJ, Carneiro MO, Auwera GAV der, Kling DE, Gauthier LD, Levy-Moonshine A, Roazen D, Shakir K, Thibault J, Chandran S, Whelan C, Lek M, Gabriel S, Daly MJ, Neale B, MacArthur DG, Banks E. 2018. Scaling accurate genetic variant discovery to tens of thousands of samples. bioRxiv 201178. doi:10.1101/201178

Projecto-Garcia J, Natarajan C, Moriyama H, Weber RE, Fago A, Cheviron ZA, Dudley R, McGuire JA, Witt CC, Storz JF. 2013. Repeated elevational transitions in hemoglobin function during the evolution of Andean hummingbirds. Proc Natl Acad Sci 110:20669-20674. doi: $10.1073 /$ pnas.1315456110

Rambaut A, Drummond AJ, Xie D, Baele G, Suchard MA. 2018. Posterior summarization in Bayesian phylogenetics using Tracer 1.7. Syst Biol 67:901-904. doi:10.1093/sysbio/syy032

Rosenblum EB, Parent CE, Brandt EE. 2014. The molecular basis of phenotypic convergence. Annu Rev Ecol Evol Syst 45:203-226. doi:10.1146/annurev-ecolsys-120213-091851

Scheet P, Stephens M. 2006. A fast and flexible statistical model for large-scale population genotype data: applications to inferring missing genotypes and haplotypic phase. Am J Hum Genet 78:629-644. doi: $10.1086 / 502802$

Signor SA, Liu Y, Rebeiz M, Kopp A. 2016. Genetic convergence in the evolution of male-specific color patterns in Drosophila. Curr Biol 26:2423-2433. doi:10.1016/j.cub.2016.07.034

Simão FA, Waterhouse RM, Ioannidis P, Kriventseva EV, Zdobnov EM. 2015. BUSCO: assessing genome assembly and annotation completeness with single-copy orthologs. Bioinformatics 31:3210-3212. doi:10.1093/bioinformatics/btv351

Smit A, Hubley R. 2008. RepeatModeler Open-1.0.

Smit A, Hubley R, Green P. 2013. RepeatMasker Open-4.0.

Stamatakis A. 2014. RAxML version 8: a tool for phylogenetic analysis and post-analysis of large phylogenies. Bioinformatics 30:1312-1313. doi:10.1093/bioinformatics/btu033

Stange M, Sánchez-Villagra MR, Salzburger W, Matschiner M. 2018. Bayesian divergence-time estimation with genome-wide single-nucleotide polymorphism data of sea catfishes (Ariidae) supports Miocene closure of the Panamanian Isthmus. Syst Biol 67:681-699. doi:10.1093/sysbio/syy006

Steiner CC, Rompler H, Boettger LM, Schoneberg T, Hoekstra HE. 2009. The genetic basis of phenotypic convergence in beach mice: similar pigment patterns but different genes. Mol Biol Evol 26:35-45. doi: 10.1093/molbev/msn218

Steiner CC, Weber JN, Hoekstra HE. 2007. Adaptive variation in beach mice produced by two interacting pigmentation genes. PLoS Biol 5:1880-1889. doi:10.1371/journal.pbio.0050219

Stern DL, Orgogozo V. 2008. The loci of evolution: How predictable is genetic evolution? Evolution 62:2155-2177. doi:10.1111/j.1558-5646.2008.00450.x

Stern DL, Orgogozo V. 2009. Is genetic evolution predictable? Science 323:746-752.

Sumner FB. 1926. An analysis of geographic variation in mice of the Peromyscus polionotus group from Florida and Alabama. J Mamm 7:149-184.

Tang H, Zhang X, Miao C, Zhang J, Ming R, Schnable JC, Schnable PS, Lyons E, Lu J. 2015. ALLMAPS: robust scaffold ordering based on multiple maps. Genome Biol 16:1-15. doi:10.1186/s13059-014-0573-1

Terhorst J, Kamm JA, Song YS. 2016. Robust and scalable inference of population history from hundreds of unphased whole genomes. Nat Genet 49:303-309. doi:10.1038/ng.3748

Thompson AC, Capellini TD, Guenther CA, Chan YF, Infante CR, Menke DB, Kingsley DM. 2018. A novel enhancer near the Pitx1 gene influences development and evolution of pelvic appendages in vertebrates. eLife 7:e38555. doi:10.7554/eLife.38555

Turner SD. 2018. qqman: an R package for visualizing GWAS results using Q-Q and manhattan plots. $J$ Open Source Softw 3:731. doi:10.21105/joss.00731

Uchimura A, Higuchi M, Minakuchi Y, Ohno M, Toyoda A, Fujiyama A, Miura I, Wakana S, Nishino J, Yagi T. 2015. Germline mutation rates and the long-term phenotypic effects of mutation 
accumulation in wild-type laboratory mice and mutator mice. Genome Res 25:1-10. doi:10.1101/gr.186148.114.25

Uy JAC, Cooper EA, Cutie S, Concannon MR, Poelstra JW, Moyle RG, Filardi CE. 2016. Mutations in different pigmentation genes are associated with parallel melanism in island flycatchers. Proc Royal Soc B 283:20160731. doi:10.1098/rspb.2016.0731

Vickrey AI, Bruders R, Kronenberg Z, Mackey E, Bohlender RJ, Maclary ET, Maynez R, Osborne EJ, Johnson KP, Huff CD, Yandell M, Shapiro MD. 2018. Introgression of regulatory alleles and a missense coding mutation drive plumage pattern diversity in the rock pigeon. eLife 7:e34803. doi:10.7554/eLife.34803

Vignieri SN, Larson JG, Hoekstra HE. 2010. The selective advantage of crypsis in mice. Evolution 64:2153-2158. doi: 10.1111/j.1558-5646.2010.00976.x

Vrieling H, Duhl DM, Millar SE, Miller KA, Barsh GS. 1994. Differences in dorsal and ventral pigmentation result from regional expression of the mouse agouti gene. Proc Natl Acad Sci 91:5667-5671. doi:10.1073/pnas.91.12.5667

Weber JN, Peterson BK, Hoekstra HE. 2013. Discrete genetic modules are responsible for complex burrow evolution in Peromyscus mice. Nature 493:402-405. doi:10.1038/nature11816

Wittkopp PJ, Kalay G. 2011. Cis-regulatory elements: molecular mechanisms and evolutionary processes underlying divergence. Nat Rev Genet 13:59-69. doi:10.1038/nrg3095

Zamani N, Russell P, Lantz H, Hoeppner MP, Meadows JR, Vijay N, Mauceli E, di Palma F, LindbladToh K, Jern P, Grabherr MG. 2013. Unsupervised genome-wide recognition of local relationship patterns. BMC Genomics 14:347. doi:10.1186/1471-2164-14-347

Zhen Y, Aardema ML, Medina EM, Schumer M, Andolfatto P. 2012. Parallel molecular evolution in an herbivore community. Science 337:1634-1638. doi:10.1126/science.1226630 


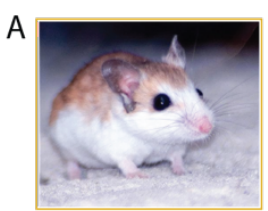

Gulf

beach mouse
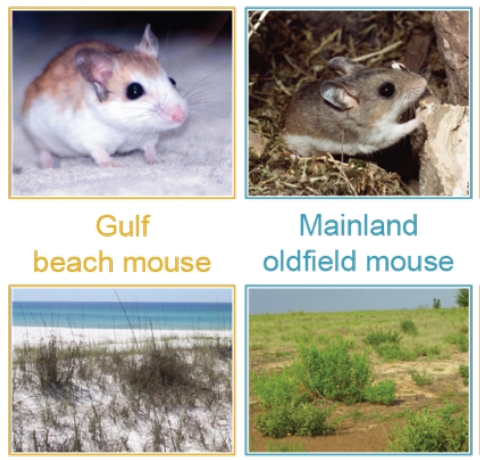

Mainland oldfield mouse

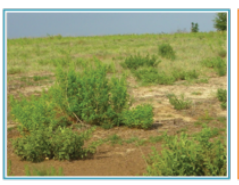

C

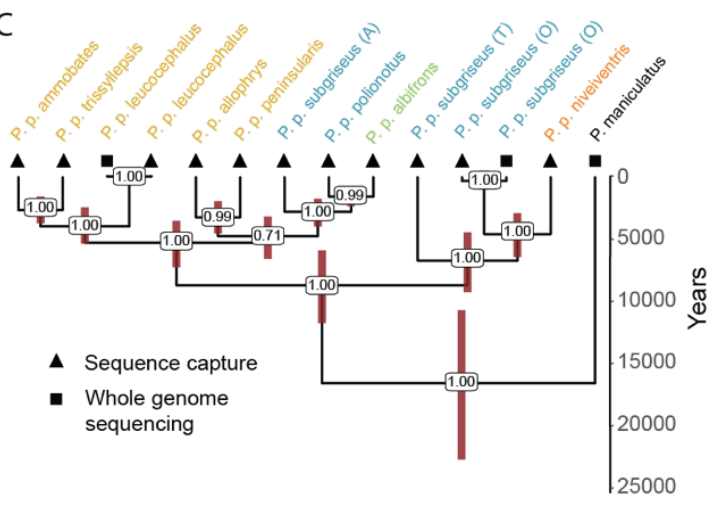

B
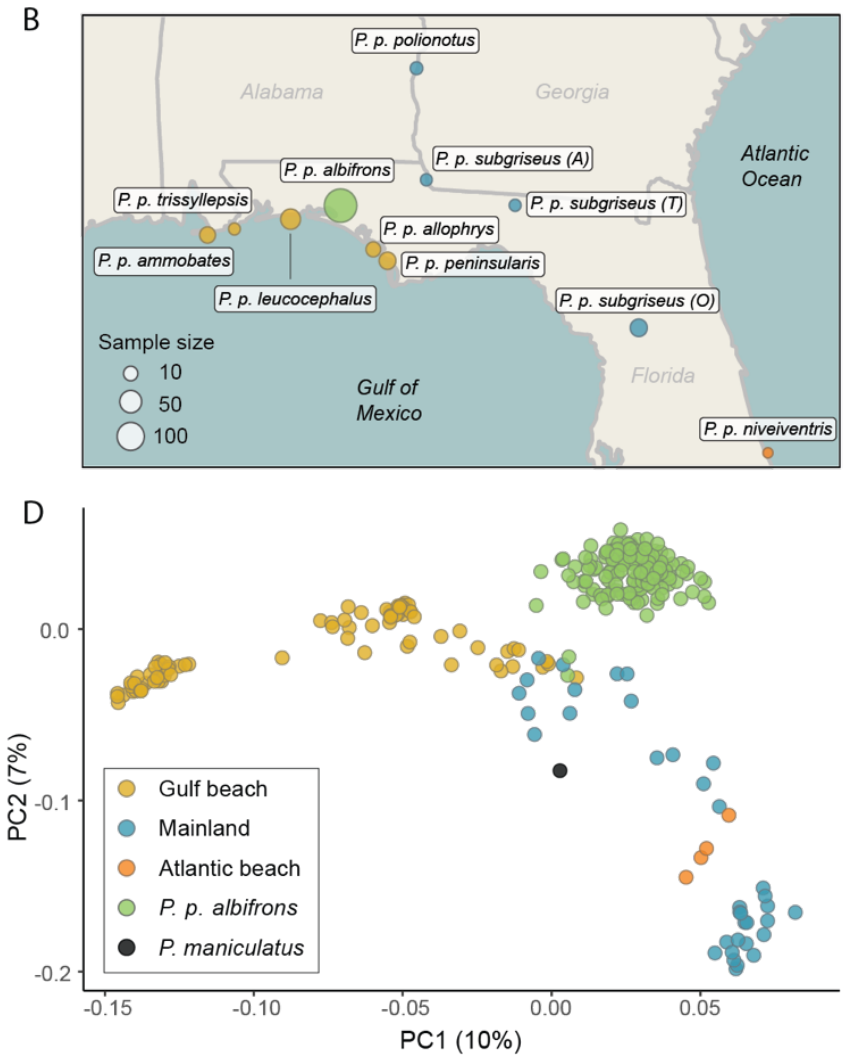

Figure 1. Distribution and relationships of beach and mainland subspecies of $P$. polionotus. A. Representative images of beach and mainland subspecies of $P$. polionotus as well as corresponding habitats. B. Map of the southeastern United States showing sampling locations of populations included in this study (see Table S1 for details). Sample sizes are indicated in parentheses; the area of each circle corresponds to sample size. $P$. p. subgriseus was sampled from three locations: $\mathrm{O}=$ Ocala, $\mathrm{A}=$ Apalachee, $\mathrm{T}=$ Tall Timbers Research Station. C. Time-scaled phylogeny of sampled populations. Numbers at nodes represent bootstrap support; red bars $95 \%$ confidence intervals of divergence time. Populations are annotated with one of two sequencing strategies used in this study. D. The first two dimensions of a principal component analysis (PCA) based on genotype probabilities; each dot represents an individual with sample sizes given in B. 
A
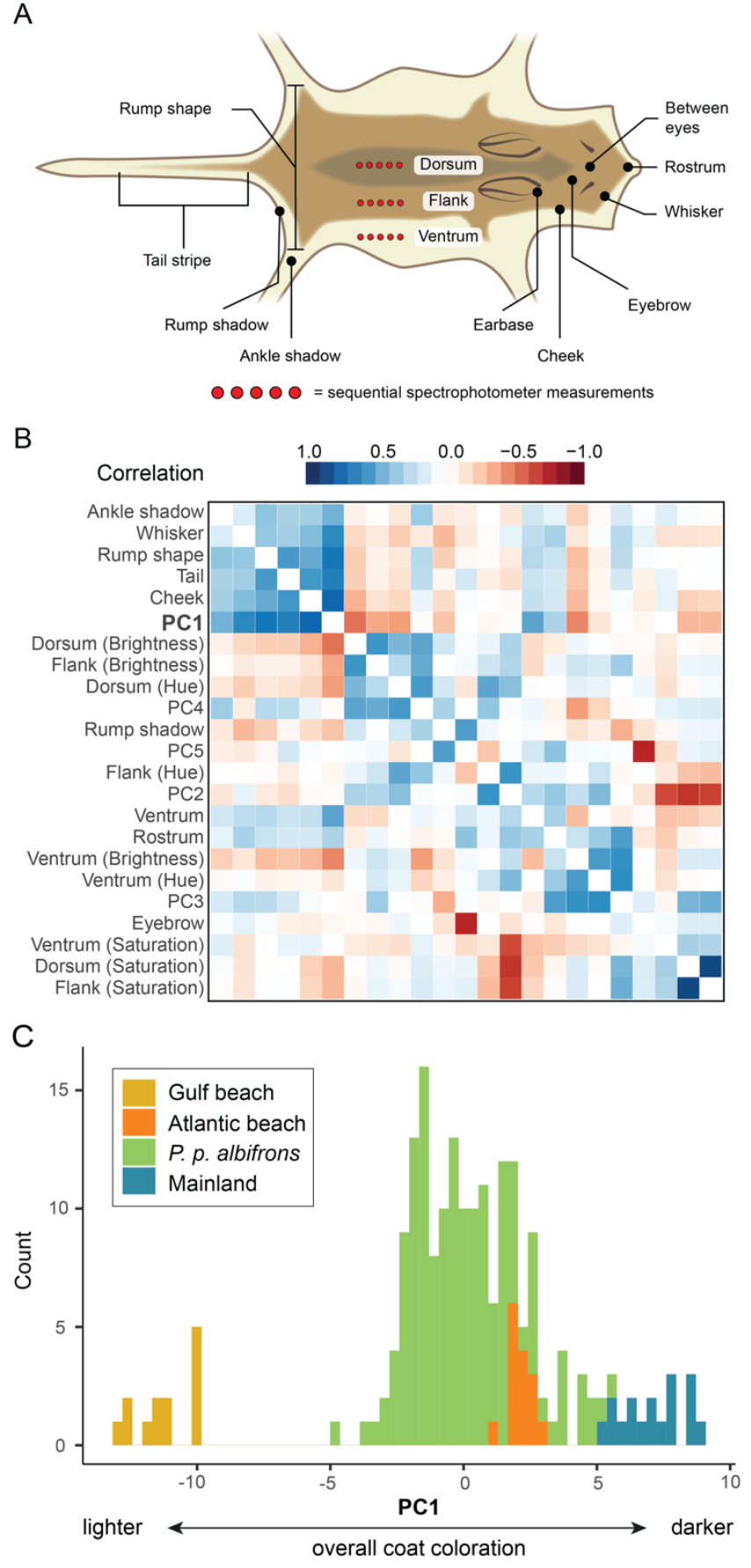

Figure 2. Phenotypic variation in the $\boldsymbol{P}$. p. albifrons population. A. Cartoon showing traits used to characterize pigment and pattern variation in museum specimens, categorical scores (black) and spectrophotometric measures (red; see Methods for details). B. Pairwise correlation among pigmentation traits and the first 5 phenotypic PCs in albifrons mice $(n=168)$. Color indicates direction and strength of the correlation. Asterisks denote significance: $*=p<0.05, * *=p<0.01, * * *=p<0.001$. PC1 is highlighted by dashed lines. Invariant traits are not shown. C. Frequency distribution of PC1 scores for albifrons mice as well as representative Gulf $(n=13)$, Mainland $(n=17)$, and Atlantic $(n=15)$ mice. 


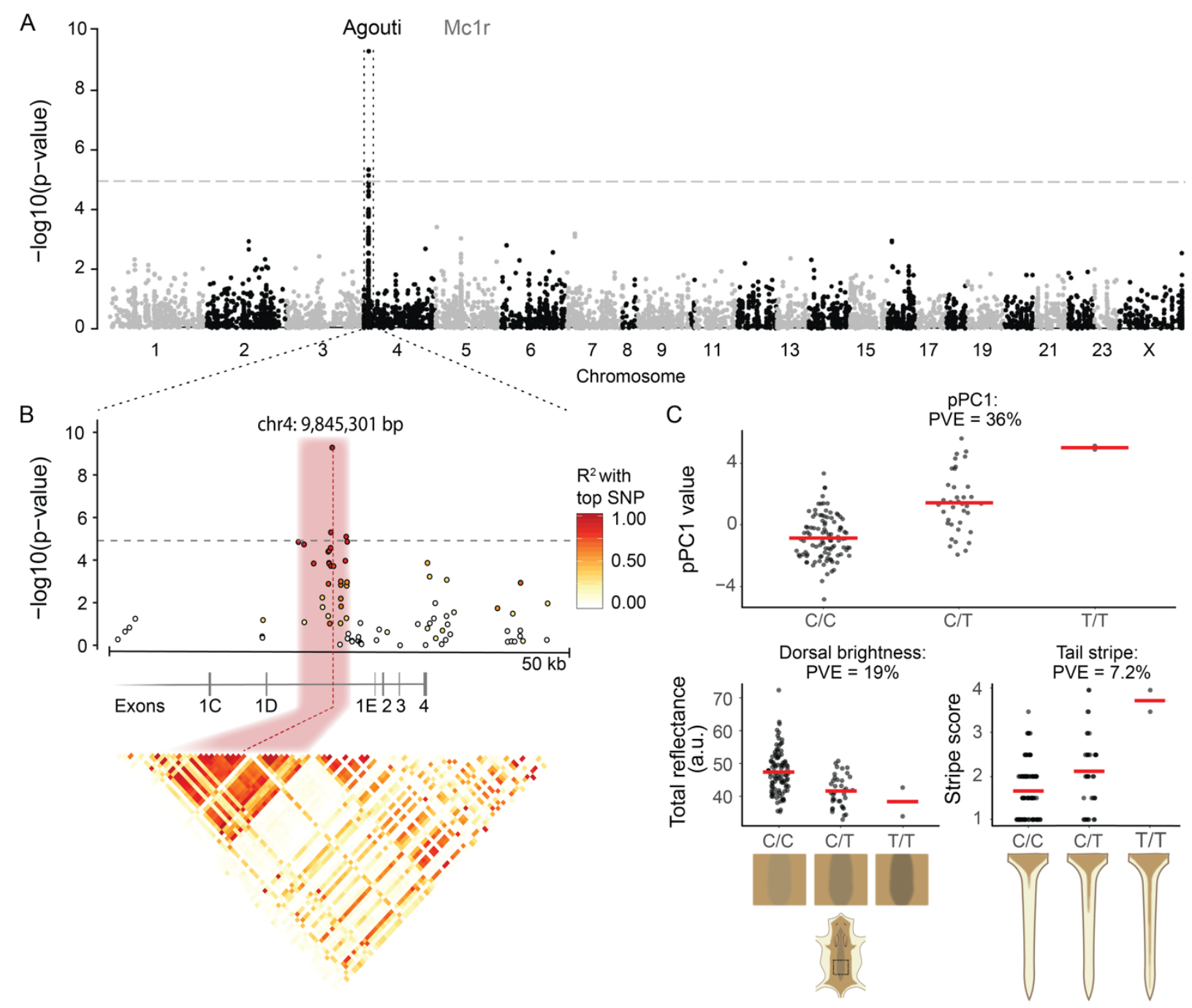

Figure 3. Genotype-phenotype associations in the Agouti locus. A. A single peak on chromosome 4 that exceeds the genome-wide significance threshold (dashed line) associates with variation in phenotypic PC1. No association observed in Mclr. B. Zoom in of the Agouti association peak. Dots represent variants; color represents the strength of linkage disequilibrium (LD) with the most highly associated SNP variant at chr4:9,845,301 bp. A single $\sim 2 \mathrm{~kb}$ region (pink) shows high levels of LD. Correlation matrix below displays pairwise LD between all variants in the $50 \mathrm{~kb}$ region. C. Distribution of $\mathrm{pPC} 1$ scores (above) and two representative traits (below) by genotype at chr4:9,845,301 bp. Red lines indicate mean trait value by genotype. PVE = percent variance explained. Cartoons illustrate differences in traits by genotype. 


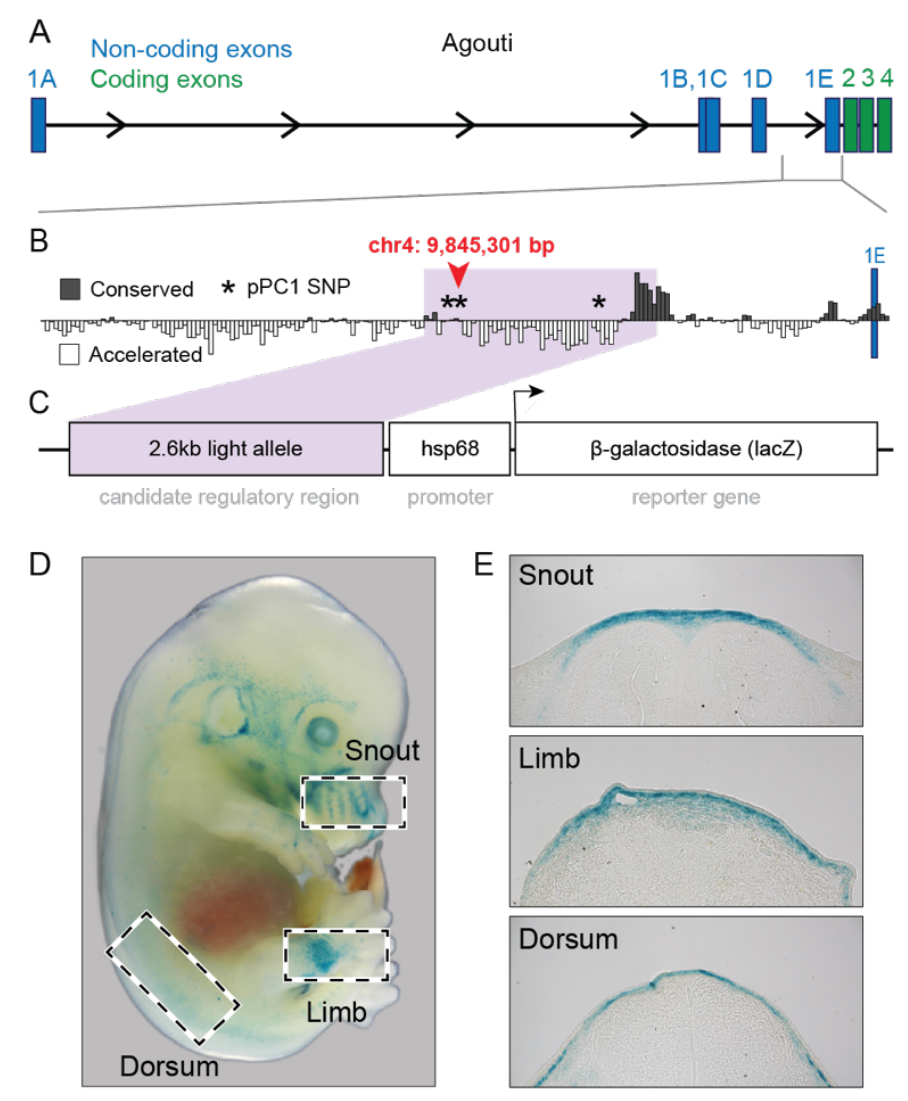

Figure 4. Location, conservation, and activity of candidate Agouti regulatory region. A. Coding structure of the $\sim 180 \mathrm{~kb}$ Peromyscus Agouti locus, including non-coding (blue) and coding (green) exons. B. PhyloP sequence conservation amongst 27 rodent species in the $10 \mathrm{~kb}$ encompassing the SNP most highly associated with pPC1 (chr4:9,845,301); this SNP and 2 others with a significant pPC1 association are denoted by asterisks (*). Purple shading highlights the $2.6 \mathrm{~kb}$ region cloned into the lac $Z$ reporter plasmid. C. Structure of lacZ reporter construct. D. Stage E14.5 transgenic Mus (FVB/NJ) embryo stained for lac $Z$ expression (blue). E. Three tissue sections showing lac $Z$ expression localized to the dermis. 


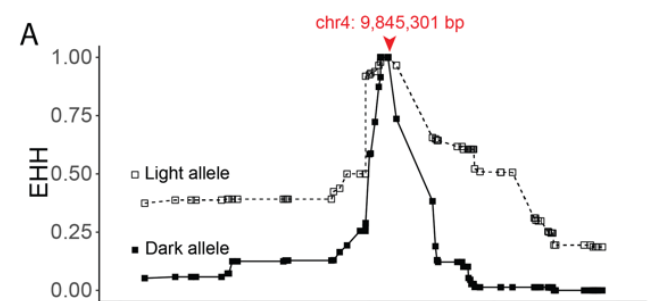

$\mathrm{B}$
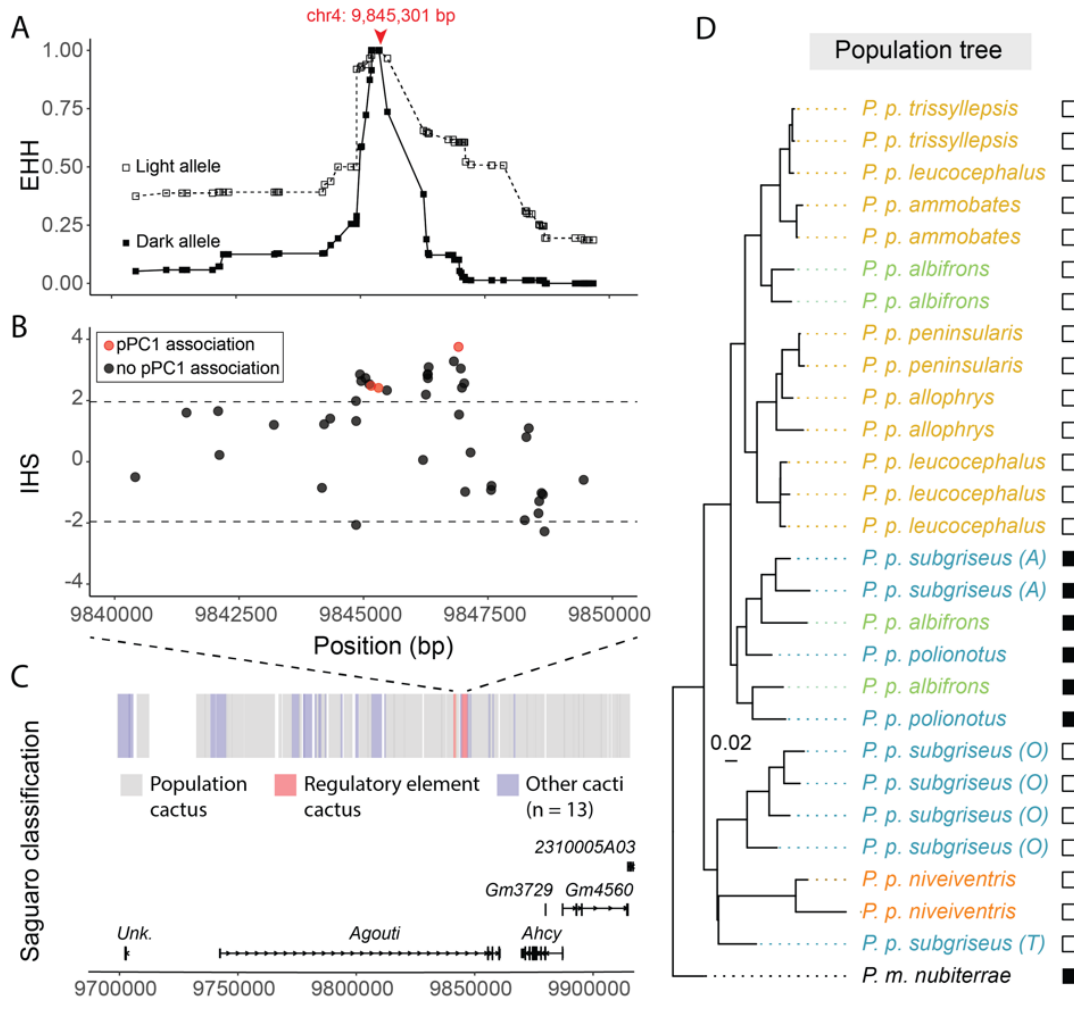

Regulatory element tree

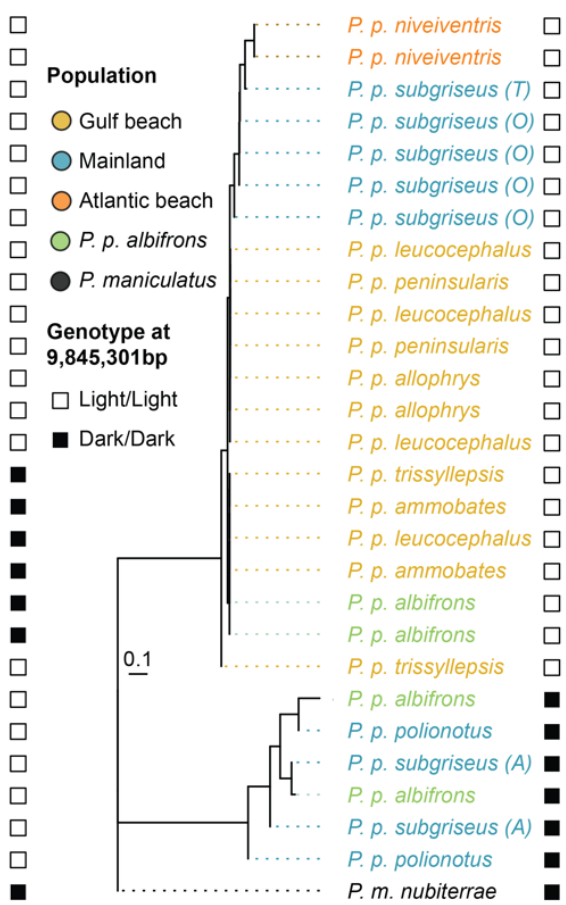

Figure 5. Evolutionary history of the derived light Agouti allele. A. Extended haplotype homozygosity $(\mathrm{EHH})$ decay plot of $10 \mathrm{~kb}$ within the Agouti locus, showing that the light allele maintains higher levels of homozygosity than the dark allele around the top-associated SNP (chr4:9,845,301 bp), consistent with a signal of positive selection. B. Integrated haplotype score (IHS) calculated for the same Agouti region. Values $>1.96$ indicate statistically significant EHH for the reference allele $(\mathrm{p}<0.05)$. C. Saguaro-based classification of local relationships across Agouti. Regions that fit to a common single topology ("Population cactus") are shown in grey. Saguaro independently identified a unique topology ("Regulatory element cactus") shown in pink, spanning two neighboring regions of 636 bp (position $9,841,443$ to $9,842,079 \mathrm{bp}$ ) and $2171 \mathrm{bp}(9,844,852$ to $9,847,023 \mathrm{bp})$, including the top-associated SNP (chr4:9,845,301 bp). D. Cactus topologies using $P$. maniculatus as outgroup. The population cactus topology closely matches the population tree (shown in Fig. 1C), while the regulatory element cactus topology separates individuals homozygous for the light or dark Agouti haplotypes, with internal branch lengths suggesting a recent origin of the light Agouti allele. 


\section{Supplementary Materials for}

\section{A novel enhancer of Agouti contributes to parallel evolution of cryptically colored beach mice}

T. Brock Wooldridge, Andreas F. Kautt, Jean-Marc Lassance, Sade McFadden, Vera S. Domingues, Ricardo Mallarino, Hopi E. Hoekstra

Correspondence to: hoekstra@oeb.harvard.edu

\section{This file includes:}

Tables S1 to S5

Figures $\mathrm{S} 1$ to $\mathrm{S} 6$ 
Table S1. Sampling information. List of species, subspecies and populations included in this study. "Collector" points to information for the precise sampling method, time, and place. Primary collector initials are as follows: EPK = Evan Kingsley, NLB = Nicole Bedford, VSD = Vera Domingues. "Sequencing strategy" refers to either WGS = whole genome sequencing (highlighted in grey) or Seqcapture $=$ targeted sequence capture array.

\begin{tabular}{|c|c|c|c|c|c|}
\hline Taxonomy & $\begin{array}{l}\text { Collectors/ } \\
\text { Publications }\end{array}$ & Latitude & Longitude & No. samples & $\begin{array}{l}\text { Sequencing } \\
\text { strategy }\end{array}$ \\
\hline P. polionotus ammobates & Mullen et al. 2009 & 30.229978 & -87.814703 & 15 & Seqcapture \\
\hline P. polionotus allophrys & Mullen et al. 2009 & 30.077795 & -85.647814 & 11 & Seqcapture \\
\hline P. polionotus leucocephalus & NLB & 30.397536 & -86.729057 & 15 & WGS \\
\hline P. polionotus leucocephalus & Mullen et al. 2009 & 30.397536 & -86.729057 & 20 & Seqcapture \\
\hline P. maniculatus nubiterrae & EPK & 40.33 & -79.27 & 1 & Seqcapture \\
\hline P. polionotus trisyllepsis & Mullen et al. 2009 & 30.29371 & -87.463557 & 5 & Seqcapture \\
\hline P. polionotus subgriseus & VSD & 29.1828333 & -81.795 & 15 & WGS \\
\hline P. polionotus albifrons & VSD & 30.5411 & -86.075717 & 168 & Seqcapture \\
\hline P. polionotus & Domingues et al. 2012 & 31.995717 & -85.082967 & 6 & Seqcapture \\
\hline P. polionotus subgriseus (A) & Domingues et al. 2012 & 30.814577 & -84.954529 & 5 & Seqcapture \\
\hline P. polionotus subgriseus $(\mathrm{T})$ & Domingues et al. 2012 & 31.6459 & -84.225 & 5 & Seqcapture \\
\hline P. polionotus subgriseus $(\mathrm{O})$ & Domingues et al. 2012 & 29.207927 & -81.740378 & 5 & Seqcapture \\
\hline P. polionotus peninsularis & Mullen et al. 2009 & 29.957198 & -85.462412 & 19 & Seqcapture \\
\hline P. polionotus niveiventris & Steiner et al. 2009 & 27.923493 & -80.488186 & 4 & Seqcapture \\
\hline
\end{tabular}


Table S2. Regulatory elements in Agouti. P. polionotus-based coordinates (HU_Ppol1.3.3) of regulatory features lifted over from the ENSEMBL Mus musculus genome (GRCm39). Features found $\sim 10 \mathrm{~kb}$ upstream and downstream of the $2 \mathrm{~kb}$ candidate region are shown.

\begin{tabular}{|c|c|c|c|c|c|c|c|}
\hline $\begin{array}{l}P \text {. polionotus } \\
\text { chromosome }\end{array}$ & $\begin{array}{l}\text { P. polionotus } \\
\text { start (bp) }\end{array}$ & $\begin{array}{l}\text { P. polionotus } \\
\text { end }(\mathrm{bp})\end{array}$ & $\begin{array}{l}\text { M. musculus } \\
\text { chromosome }\end{array}$ & $\begin{array}{l}\text { M. musculus } \\
\text { start (bp) }\end{array}$ & $\begin{array}{l}\text { M. musculus } \\
\text { end (bp) }\end{array}$ & ENSEMBL ID & $\begin{array}{l}\text { ENSEMBL } \\
\text { element type }\end{array}$ \\
\hline chr4 & 9834661 & 9834859 & $\operatorname{chr} 2$ & 154872801 & 154873001 & ENSMUSR00000830170 & $\begin{array}{l}\text { Predicted } \\
\text { enhancer }\end{array}$ \\
\hline $\operatorname{chr} 4$ & 9842998 & 9843607 & chr2 & 154880275 & 154880693 & ENSMUSR00000636464 & $\begin{array}{l}\text { Transcription } \\
\text { factor binding }\end{array}$ \\
\hline $\operatorname{chr} 4$ & 9850467 & 9851000 & chr2 & 154887001 & 154887600 & ENSMUSR00000830172 & $\begin{array}{l}\text { Predicted } \\
\text { enhancer }\end{array}$ \\
\hline chr4 & 9852071 & 9852243 & $\operatorname{chr} 2$ & 154888801 & 154889000 & ENSMUSR00000830173 & $\begin{array}{l}\text { CTCF Binding } \\
\text { Site }\end{array}$ \\
\hline
\end{tabular}


Table S3. Population-level frequency of light allele. Each species is provided with its source location. Frequency of the light allele is calculated as the proportion of haplotypes in a population that have the light-associated allele at chr4:9,845,301 bp.

\begin{tabular}{|c|c|c|}
\hline Species & Location & $\begin{array}{c}\text { Frequency of } \\
\text { light Agouti allele }\end{array}$ \\
\hline P.p. allophrys & Gulf Coast Beach & 1 \\
\hline P.p. ammobates & Gulf Coast Beach & 1 \\
\hline P.p. leucocephalus & Gulf Coast Beach & 1 \\
\hline P.p. trisyllepsis & Gulf Coast Beach & 1 \\
\hline P.p.peninsularis & Gulf Coast Beach & 1 \\
\hline P.p. niveiventris & Atlantic Coast Beach & 1 \\
\hline P. m. nubiterrae & Mainland (Outgroup) & 0 \\
\hline P.p. albifrons & Mainland & 0.86 \\
\hline P.p.polionotus & Mainland & 0 \\
\hline P.p. subgriseus $(A)$ & Mainland & 0 \\
\hline P.p. subgriseus $(O)$ & Mainland & 1 \\
\hline P. p. subgriseus (T) & Mainland & 1 \\
\hline
\end{tabular}


Table S4. Transcription factor binding sites overlapping variant positions in the regulatory element of $\boldsymbol{P}$. p. albifrons. "Position" includes only sites on chr4 in the tested regulatory element $(9,844,852 \mathrm{bp}-$ $9,847,500 \mathrm{bp}$ ) that are variant in $P$. p. albifrons with a minor allele frequency (MAF) $>0.05$. Both "Reference allele" and "Alternate allele" are relative to the $P$. p. subgriseus reference genome (no relation to light or dark haplotypes). "Reference-specific TFs" and "Alternate-specific TFs" refer to predicted TF binding sites from JASPAR (see Methods) that are intact in the Reference allele and Alternate allele, respectively. pPC1-associated SNPs are highlighted in gray.

\begin{tabular}{|c|c|c|c|c|c|}
\hline Position & $\begin{array}{l}\text { Reference } \\
\text { allele }\end{array}$ & $\begin{array}{l}\text { Alternate } \\
\text { allele }\end{array}$ & $\begin{array}{l}\text { Alternate } \\
\text { allele } \\
\text { frequency }\end{array}$ & Reference-specific TFs & Alternate-specific TFs \\
\hline 9844852 & G & A & 0.0648148 & Foxo3;Neurog1 & Arid5a \\
\hline 9844869 & $\mathrm{GC}$ & G & 0.168712 & Zfp335 & Rhox11 \\
\hline 9844930 & G & A & 0.171975 & -- & Rhox11 \\
\hline 9844954 & A & G & 0.159091 & -- & Mitf \\
\hline 9844955 & G & GTC & 0.155844 & -- & Mitf \\
\hline 9845040 & $\mathrm{~T}$ & A & 0.154762 & -- & Nkx3-2 \\
\hline 9845116 & $\mathrm{C}$ & $\mathrm{T}$ & 0.140741 & Dlx5 & Nkx2-5 \\
\hline 9845136 & G & GA & 0.142336 & Foxn1 & -- \\
\hline 9845152 & G & A & 0.150735 & Arnt::Hif1a;Hes1 & $\operatorname{Pax} 2$ \\
\hline 9845301 & $\mathrm{C}$ & $\mathrm{T}$ & 0.140411 & -- & Nkx3-2 \\
\hline 9845470 & $\mathrm{C}$ & $\mathrm{T}$ & 0.127049 & -- & -- \\
\hline 9846196 & $\mathrm{C}$ & $\mathrm{T}$ & 0.208333 & Gfilb;Klf4 & Barhl1;Bcl11b \\
\hline 9846254 & G & A & 0.0620915 & -- & $\begin{array}{l}\text { Atoh1;Bhlha15;Msgn1;Myc; } \\
\text { Npas2;Twist2 }\end{array}$ \\
\hline 9846286 & A & G & 0.123333 & $\begin{array}{l}\text { Atoh1;Bhlha15;Bhlhe40;Fos: } \\
\text { :Jun;Foxj2;Foxo1;Foxo3;Mitf } \\
\text {;Myc;Npas2;Pax2;Twist2 }\end{array}$ & -- \\
\hline 9846292 & $\mathrm{~T}$ & $\mathrm{C}$ & 0.125 & $\begin{array}{l}\text { Atf3;Atoh1;Bhlha15;Bhlhe40 } \\
\text {;Fos::Jun;Foxj2;Foxo1;Foxo3 } \\
\text {;Jun;Mitf;Myc;Nkx3- } \\
\text { 2;Npas2;Twist2 }\end{array}$ & $\mathrm{Nr} 2 \mathrm{e} 1$ \\
\hline 9846293 & G & A & 0.121622 & $\begin{array}{l}\text { Atf3;Atoh1;Bhlha15;Bhlhe40 } \\
\text {;Fos::Jun;Foxj2;Foxo1;Foxo3 } \\
\text {;Jun;Mitf;Myc;Nkx3- } \\
\text { 2;Nppas2;Twist2 }\end{array}$ & $\mathrm{Nr} 2 \mathrm{e} 1$ \\
\hline 9846308 & $\mathrm{~T}$ & $\mathrm{C}$ & 0.127586 & Atoh1 & Hes2 \\
\hline 9846815 & G & A & 0.143357 & -- & Nkx2-5 \\
\hline 9846908 & A & G & 0.171975 & Cebpa;Mafb & Elf5;Hand1::Tcf3;Hic1 \\
\hline 9846919 & $\mathrm{C}$ & $\mathrm{T}$ & 0.0796178 & -- & -- \\
\hline 9846954 & $\mathrm{~T}$ & G & 0.102564 & -- & -- \\
\hline 9846977 & $\mathrm{C}$ & $\mathrm{T}$ & 0.115385 & -- & Barhl1;Neurog1;Nkx2-5 \\
\hline 9847023 & $\mathrm{~T}$ & G & 0.153846 & Elf5;Gata1 & Rfx6 \\
\hline 9847042 & $\mathrm{~T}$ & G & 0.730263 & -- & Hand1::Tcf3 \\
\hline 9847150 & A & G & 0.788591 & Barhl1;Nkx2-5 & Myb;Stat6;Tcf3 \\
\hline
\end{tabular}


Table S5. Museum accession information for all samples included in study. "Sample ID" refers to ID used by authors in this study, while "Collection ID" refers to the ID used by the institution where samples are accessioned. "Collection" refers to either $\mathrm{MCZ}=$ Harvard Museum of Comparative Zoology, or FLMNH $=$ Florida Museum of Natural History.

\begin{tabular}{|c|c|c|c|}
\hline Sample ID & Species & Collection & Collection ID \\
\hline 01_NB_F_EPK04 & P.m.nubiterrae & not accessioned & NA \\
\hline VSD142 & P.p.albifrons & MCZ & 68140 \\
\hline VSD143 & P.p.albifrons & MCZ & 68141 \\
\hline VSD195 & P.p.albifrons & MCZ & 68192 \\
\hline VSD196 & P.p.albifrons & $\mathrm{MCZ}$ & 68193 \\
\hline VSD197 & P.p.albifrons & $\mathrm{MCZ}$ & 68194 \\
\hline VSD198 & P.p.albifrons & MCZ & 68195 \\
\hline VSD199 & P.p. albifrons & $\mathrm{MCZ}$ & 68196 \\
\hline VSD200 & P.p. albifrons & MCZ & 68197 \\
\hline VSD201 & P.p.albifrons & $\mathrm{MCZ}$ & 68198 \\
\hline VSD202 & P.p.albifrons & MCZ & 68199 \\
\hline VSD203 & P.p.albifrons & $\mathrm{MCZ}$ & 68200 \\
\hline VSD204 & P.p.albifrons & $\mathrm{MCZ}$ & 68201 \\
\hline VSD205 & P.p.albifrons & MCZ & 68202 \\
\hline VSD207 & P.p.albifrons & $\mathrm{MCZ}$ & 68204 \\
\hline VSD208 & P.p.albifrons & MCZ & 68205 \\
\hline VSD209 & P.p.albifrons & $\mathrm{MCZ}$ & 68206 \\
\hline VSD210 & P.p.albifrons & MCZ & 68207 \\
\hline VSD211 & P.p.albifrons & $\mathrm{MCZ}$ & 68208 \\
\hline VSD212 & P.p.albifrons & $\mathrm{MCZ}$ & 68209 \\
\hline VSD214 & P.p.albifrons & MCZ & 68211 \\
\hline VSD215 & P.p.albifrons & MCZ & 68212 \\
\hline VSD216 & P.p.albifrons & MCZ & 68213 \\
\hline VSD217 & P.p. albifrons & MCZ & 68214 \\
\hline VSD218 & P.p.albifrons & $\mathrm{MCZ}$ & 68215 \\
\hline VSD219 & P.p.albifrons & MCZ & 68216 \\
\hline VSD220 & P.p.albifrons & $\mathrm{MCZ}$ & 68217 \\
\hline VSD221 & P.p.albifrons & MCZ & 68218 \\
\hline VSD222 & P.p. albifrons & MCZ & 68219 \\
\hline VSD223 & P.p.albifrons & $\mathrm{MCZ}$ & 68220 \\
\hline VSD224 & P.p.albifrons & MCZ & 68221 \\
\hline VSD225 & P.p.albifrons & $\mathrm{MCZ}$ & 68222 \\
\hline VSD226 & P.p. albifrons & MCZ & 68223 \\
\hline VSD227 & P.p.albifrons & MCZ & 68224 \\
\hline VSD228 & P.p.albifrons & MCZ & 68225 \\
\hline VSD229 & P.p.albifrons & MCZ & 68226 \\
\hline VSD230 & P.p. albifrons & MCZ & 68227 \\
\hline VSD231 & P.p. albifrons & MCZ & 68228 \\
\hline VSD233 & P.p.albifrons & MCZ & 68230 \\
\hline VSD234 & P.p.albifrons & MCZ & 68231 \\
\hline VSD235 & P.p.albifrons & $\mathrm{MCZ}$ & 68232 \\
\hline VSD236 & P.p.albifrons & MCZ & 68233 \\
\hline VSD237 & P.p.albifrons & MCZ & 68234 \\
\hline VSD238 & P.p. albifrons & MCZ & 68235 \\
\hline VSD239 & P.p.albifrons & MCZ & 68236 \\
\hline VSD240 & P.p.albifrons & MCZ & 68237 \\
\hline VSD241 & P.p.albifrons & MCZ & 68238 \\
\hline VSD242 & P.p.albifrons & $\mathrm{MCZ}$ & 68239 \\
\hline VSD243 & P.p.albifrons & MCZ & 68240 \\
\hline VSD244 & P.p.albifrons & MCZ & 68241 \\
\hline VSD245 & P.p.albifrons & MCZ & 68242 \\
\hline VSD246 & P.p.albifrons & MCZ & 68243 \\
\hline VSD247 & P.p.albifrons & MCZ & 68244 \\
\hline VSD248 & P.p. albifrons & MCZ & 68245 \\
\hline VSD249 & P.p.albifrons & MCZ & 68246 \\
\hline VSD250 & P.p.albifrons & $\mathrm{MCZ}$ & 68247 \\
\hline VSD251 & P.p.albifrons & MCZ & 68248 \\
\hline VSD252 & P.p. albifrons & MCZ & 68249 \\
\hline VSD253 & P.p.albifrons & $\mathrm{MCZ}$ & 68250 \\
\hline VSD254 & P.p.albifrons & MCZ & 68251 \\
\hline VSD256 & P.p.albifrons & MCZ & 68253 \\
\hline
\end{tabular}




\begin{tabular}{|c|}
\hline VSD257 \\
\hline VSD259 \\
\hline VSD260 \\
\hline VSD261 \\
\hline VSD262 \\
\hline VSD263 \\
\hline VSD264 \\
\hline VSD265 \\
\hline VSD266 \\
\hline VSD267 \\
\hline VSD268 \\
\hline VSD269 \\
\hline VSD270 \\
\hline VSD271 \\
\hline VSD272 \\
\hline VSD273 \\
\hline VSD274 \\
\hline VSD275 \\
\hline VSD276 \\
\hline VSD278 \\
\hline VSD279 \\
\hline VSD280 \\
\hline VSD281 \\
\hline VSD282 \\
\hline VSD283 \\
\hline VSD284 \\
\hline VSD285 \\
\hline VSD286 \\
\hline VSD287 \\
\hline VSD288 \\
\hline VSD289 \\
\hline VSD292 \\
\hline VSD293 \\
\hline VSD294 \\
\hline VSD295 \\
\hline VSD296 \\
\hline VSD298 \\
\hline VSD299 \\
\hline VSD307 \\
\hline VSD308 \\
\hline VSD309 \\
\hline VSD310 \\
\hline VSD311 \\
\hline VSD312 \\
\hline VSD313 \\
\hline VSD314 \\
\hline VSD315 \\
\hline VSD316 \\
\hline VSD317 \\
\hline VSD318 \\
\hline VSD319 \\
\hline VSD320 \\
\hline VSD321 \\
\hline VSD322 \\
\hline VSD323 \\
\hline VSD324 \\
\hline VSD331 \\
\hline VSD332 \\
\hline VSD333 \\
\hline VSD334 \\
\hline VSD335 \\
\hline VSD336 \\
\hline VSD337 \\
\hline VSD338 \\
\hline VSD339 \\
\hline VSD340 \\
\hline VSD341 \\
\hline VSD342 \\
\hline VSD343 \\
\hline VSD344 \\
\hline
\end{tabular}

P.p.albifrons P.p.albifrons

P.p. albifrons

P.p.albifrons

P.p.albifrons

P.p.albifrons

P.p.albifrons

P.p.albifrons

P.p.albifrons

P.p.albifrons

P.p. albifrons

P.p.albifrons

P.p.albifrons

P.p.albifrons

P.p.albifrons

P.p.albifrons

P.p.albifrons

P.p. albifrons

P.p.albifrons

P.p. albifrons

P.p.albifrons

P.p.albifrons

P.p.albifrons

P.p. albifrons

P.p.albifrons

P.p.albifrons

P.p.albifrons

P.p.albifrons

P.p.albifrons

P.p.albifrons

P.p.albifrons

P.p.albifrons

P.p.albifrons

P.p.albifrons

P.p.albifrons

P.p.albifrons

P.p.albifrons

P.p.albifrons

P.p.albifrons

P.p.albifrons

P.p.albifrons

P.p.albifrons

P.p.albifrons

P.p.albifrons

P.p. albifrons

P.p.albifrons

P.p.albifrons

P.p.albifrons

P.p.albifrons

P.p.albifrons

P.p.albifrons

P.p.albifrons

P.p.albifrons

P.p.albifrons

P.p.albifrons

P.p.albifrons

P.p.albifrons

P.p.albifrons

P.p.albifrons

P.p. albifrons

P.p.albifrons

P.p.albifrons

P.p.albifrons

P.p.albifrons

P.p.albifrons

P.p.albifrons

P.p.albifrons

P.p.albifrons

P.p.albifrons

P.p.albifrons
MCZ 68254

MCZ 68256

MCZ 68257

MCZ 68258

MCZ $\quad 68259$

MCZ 68260

MCZ $\quad 68261$

MCZ 68262

MCZ $\quad 68263$

MCZ 68264

MCZ $\quad 68265$

MCZ 68266

MCZ $\quad 68267$

MCZ 68268

MCZ $\quad 68269$

MCZ 68270

MCZ $\quad 68271$

MCZ 68272

MCZ $\quad 68273$

MCZ $\quad 68275$

MCZ $\quad 68276$

MCZ 68277

MCZ 68278

MCZ 68279

MCZ 68280

MCZ 68281

MCZ 68282

MCZ 68283

MCZ 68284

MCZ $\quad 68285$

$\mathrm{MCZ} \quad 68286$

$\begin{array}{ll}M C Z & 68289\end{array}$

MCZ 68290

MCZ 68291

MCZ 68292

MCZ 68293

MCZ 68295

MCZ $\quad 68296$

MCZ 68304

MCZ $\quad 68305$

MCZ 68306

MCZ $\quad 68307$

MCZ 68308

MCZ $\quad 68309$

MCZ 68310

MCZ $\quad 68311$

MCZ 68312

MCZ 68313

MCZ 68314

MCZ 68315

MCZ $\quad 68316$

MCZ 68317

MCZ 68318

MCZ 68319

MCZ $\quad 68320$

MCZ 68321

MCZ $\quad 68328$

MCZ 68329

MCZ $\quad 68330$

MCZ 68331

MCZ $\quad 68332$

MCZ 68333

MCZ $\quad 68334$

MCZ 68335

MCZ $\quad 68336$

MCZ 68337

MCZ 68338

MCZ 68339

MCZ $\quad 68340$

MCZ 68341 
bioRxiv preprint doi: https://doi.org/10.1101/2021.11.05.467454; this version posted November 5, 2021. The copyright holder for this preprint (which was not certified by peer review) is the author/funder. All rights reserved. No reuse allowed without permission.

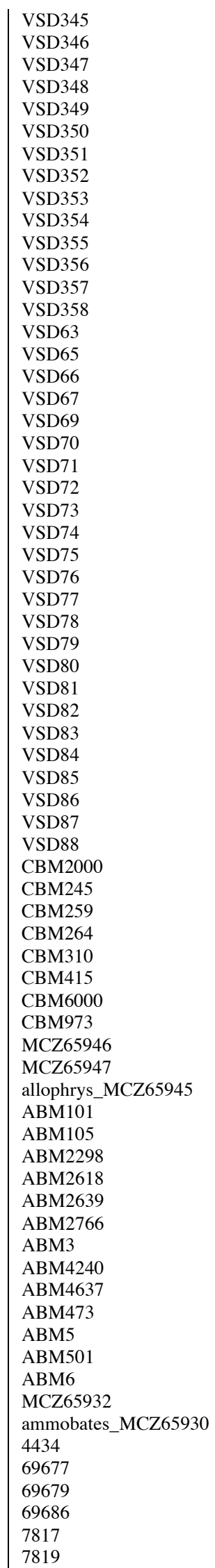

\begin{tabular}{|c|c|c|}
\hline P.p.albifrons & MCZ & 68342 \\
\hline P.p. albifrons & MCZ & 68343 \\
\hline P.p.albifrons & MCZ & 68344 \\
\hline P.p.albifrons & $\mathrm{MCZ}$ & 68345 \\
\hline P.p.albifrons & MCZ & 68346 \\
\hline P.p.albifrons & $\mathrm{MCZ}$ & 68347 \\
\hline P.p. albifrons & MCZ & 68348 \\
\hline P.p.albifrons & $\mathrm{MCZ}$ & 68349 \\
\hline P.p.albifrons & $\mathrm{MCZ}$ & 68350 \\
\hline P.p. albifrons & MCZ & 68351 \\
\hline P.p.albifrons & $\mathrm{MCZ}$ & 68352 \\
\hline P.p.albifrons & $\mathrm{MCZ}$ & 68353 \\
\hline P.p.albifrons & MCZ & 68354 \\
\hline P.p.albifrons & $\mathrm{MCZ}$ & 68355 \\
\hline P.p.albifrons & $\mathrm{MCZ}$ & 68061 \\
\hline P.p.albifrons & $\mathrm{MCZ}$ & 68063 \\
\hline P.p.albifrons & $\mathrm{MCZ}$ & 68064 \\
\hline P.p. albifrons & $\mathrm{MCZ}$ & 68065 \\
\hline P.p.albifrons & $\mathrm{MCZ}$ & 68067 \\
\hline P.p.albifrons & $\mathrm{MCZ}$ & 68068 \\
\hline P.p.albifrons & MCZ & 68069 \\
\hline P.p.albifrons & $\mathrm{MCZ}$ & 68070 \\
\hline P.p. albifrons & MCZ & 68071 \\
\hline P.p.albifrons & $\mathrm{MCZ}$ & 68072 \\
\hline P.p.albifrons & MCZ & 68073 \\
\hline P.p.albifrons & $\mathrm{MCZ}$ & 68074 \\
\hline P.p.albifrons & MCZ & 68075 \\
\hline P.p.albifrons & MCZ & 68076 \\
\hline P.p.albifrons & MCZ & 68077 \\
\hline P.p.albifrons & $\mathrm{MCZ}$ & 68078 \\
\hline P.p.albifrons & $\mathrm{MCZ}$ & 68079 \\
\hline P.p.albifrons & MCZ & 68080 \\
\hline P.p.albifrons & $\mathrm{MCZ}$ & 68081 \\
\hline P.p.albifrons & MCZ & 68082 \\
\hline P.p.albifrons & MCZ & 68083 \\
\hline P.p.albifrons & $\mathrm{MCZ}$ & 68084 \\
\hline P.p.albifrons & $\mathrm{MCZ}$ & 68085 \\
\hline P.p.albifrons & $\mathrm{MCZ}$ & 68086 \\
\hline \multicolumn{3}{|l|}{ P.p.allophrys } \\
\hline \multicolumn{3}{|l|}{ P.p. allophrys } \\
\hline \multicolumn{3}{|l|}{ P.p. allophrys } \\
\hline \multicolumn{3}{|l|}{ P.p.allophrys } \\
\hline \multicolumn{3}{|l|}{ P.p.allophrys } \\
\hline \multicolumn{3}{|l|}{ P.p.allophrys } \\
\hline \multicolumn{3}{|l|}{ P.p.allophrys } \\
\hline \multicolumn{3}{|l|}{ P.p.allophrys } \\
\hline P.p.allophrys & $\mathrm{MCZ}$ & 65946 \\
\hline P.p.allophrys & MCZ & 65947 \\
\hline P.p.allophrys & MCZ & 65945 \\
\hline \multicolumn{3}{|l|}{ P.p.ammobates } \\
\hline \multicolumn{3}{|l|}{ P.p.ammobates } \\
\hline \multicolumn{3}{|l|}{ P.p.ammobates } \\
\hline \multicolumn{3}{|l|}{ P.p.ammobates } \\
\hline \multicolumn{3}{|l|}{ P.p.ammobates } \\
\hline P.p.ammobates & & \\
\hline P.p.ammobates & & \\
\hline P.p.ammobates & & \\
\hline P.p.ammobates & & \\
\hline P.p.ammobates & & \\
\hline P.p.ammobates & & \\
\hline P.p.ammobates & & \\
\hline P.p.ammobates & & \\
\hline P.p.ammobates & MCZ & 65932 \\
\hline P.p.ammobates & MCZ & 65930 \\
\hline P.p.leucocephalus & $\mathrm{MCZ}$ & 4434 \\
\hline P.p.leucocephalus & $\mathrm{MCZ}$ & 69677 \\
\hline P.p.leисосерhalus & $\mathrm{MCZ}$ & 69679 \\
\hline P.p.leucocephalus & MCZ & 69686 \\
\hline P.p.leисосерhalus & MCZ & 7817 \\
\hline P.p.leисосерhalus & $\mathrm{MCZ}$ & 7819 \\
\hline
\end{tabular}




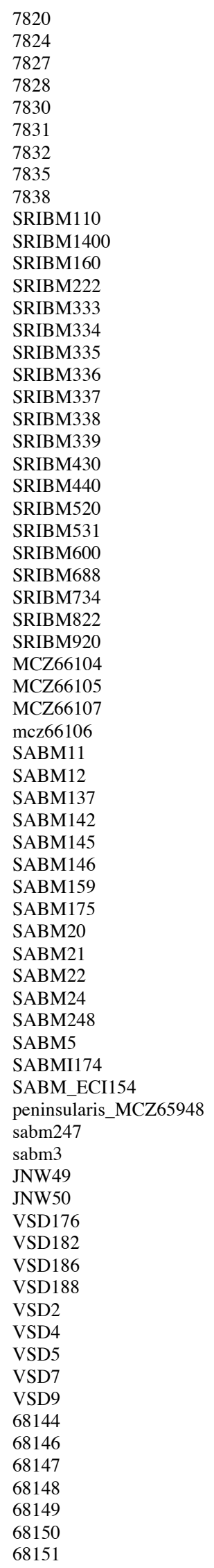

P.p. leucocephalus P.p.leucocephalus P.p. leucocephalus P.p.leucocephalus P.p.leucocephalus P.p.leucocephalus P.p.leucocephalus P.p. leucocephalus P.p.leucocephalus P.p. leucocephalus

P.p. leucocephalus P.p. leucocephalus

P.p. leucocephalus P.p. leucocephalus

P.p. leucocephalus P.p. leucocephalus

P.p. leucocephalus P.p. leucocephalus

P.p.leucocephalus P.p. leucocephalus

P.p.leucocephalus P.p. leucocephalus

P.p. leucocephalus

P.p. leucocephalus

P.p. leucocephalus

P.p. leucocephalus

P.p. leucocephalus

P.p. leucocephalus

P.p. leucocephalus

$P$. p. niveiventris

$P . p$. niveiventris

P.p. niveiventris

$P$. p. niveiventris

P.p.peninsularis

P.p.peninsularis

P.p.peninsularis

P.p.peninsularis

P.p.peninsularis

P.p.peninsularis

P.p.peninsularis

P.p.peninsularis

P.p.peninsularis

P.p.peninsularis

P.p.peninsularis

P.p.peninsularis

P.p.peninsularis

P.p.peninsularis

P.p.peninsularis

P.p.peninsularis

P.p.peninsularis

P.p. peninsularis

P.p.peninsularis

P.p.polionotus

P.p.polionotus

P.p.polionotus

P.p.polionotus

P.p.polionotus

P.p.polionotus

P.p. subgriseus (A)

P.p. subgriseus $(A)$

P.p. subgriseus $(A)$

P.p. subgriseus $(A)$

P.p. subgriseus $(A)$

$P$.p.subgriseus $(O)$

$P$.p. subgriseus $(O)$

$P$.p.subgriseus $(O)$

$P . p$. subgriseus $(O)$

$P$.p. subgriseus $(O)$

P.p. subgriseus $(O)$

$P$.p. subgriseus $(O)$
$\mathrm{MCZ}$

$\mathrm{MCZ}$

MCZ

$\mathrm{MCZ}$

MCZ

$\mathrm{MCZ}$

MCZ

MCZ

MCZ

FLMNH

FLMNH

FLMNH

FLMNH

FLMNH

FLMNH

FLMNH

FLMNH

FLMNH

FLMNH

FLMNH

FLMNH

FLMNH

FLMNH

FLMNH

FLMNH

FLMNH

FLMNH

FLMNH

FLMNH

MCZ

$\mathrm{MCZ}$

MCZ

MCZ

FLMNH

FLMNH

FLMNH

FLMNH

FLMNH

FLMNH

FLMNH

FLMNH

FLMNH

FLMNH

FLMNH

FLMNH

FLMNH

FLMNH

FLMNH

FLMNH

$\mathrm{MCZ}$

FLMNH

FLMNH

MCZ

$\mathrm{MCZ}$

$\mathrm{MCZ}$

$\mathrm{MCZ}$

MCZ

MCZ

MCZ

MCZ

MCZ

$\mathrm{MCZ}$

MCZ

$\mathrm{MCZ}$

MCZ

$\mathrm{MCZ}$

MCZ

$\mathrm{MCZ}$

$\mathrm{MCZ}$

MCZ
7820

7824

7827

7828

7830

7831

7832

7835

7838

66104

66105

66107

66106

65948

64653

64654

68174

68180

68184

68186

68002

68004

68005

68007

68009

68144

68146

68147

68148

68149

68150

68151 
bioRxiv preprint doi: https://doi.org/10.1101/2021.11.05.467454; this version posted November 5, 2021. The copyright holder for this preprint (which was not certified by peer review) is the author/funder. All rights reserved. No reuse allowed without permission.

\begin{tabular}{|c|c|c|c|}
\hline 68152 & P.p.subgriseus $(O)$ & MCZ & 68152 \\
\hline 68153 & P.p. subgriseus $(O)$ & $\mathrm{MCZ}$ & 68153 \\
\hline 68154 & P.p.subgriseus $(O)$ & $\mathrm{MCZ}$ & 68154 \\
\hline 68159 & $P . p$. subgriseus $(O)$ & MCZ & 68159 \\
\hline 68160 & P.p.subgriseus $(O)$ & MCZ & 68160 \\
\hline 68161 & P.p.subgriseus $(O)$ & MCZ & 68161 \\
\hline 68162 & P.p.subgriseus $(O)$ & $\mathrm{MCZ}$ & 68162 \\
\hline 68163 & P.p.subgriseus $(O)$ & $\mathrm{MCZ}$ & 68163 \\
\hline VSD148 & P.p. subgriseus $(O)$ & $\mathrm{MCZ}$ & 68146 \\
\hline VSD150 & P.p.subgriseus $(O)$ & $\mathrm{MCZ}$ & 68148 \\
\hline VSD154 & P.p.subgriseus $(O)$ & $\mathrm{MCZ}$ & 68152 \\
\hline VSD156 & P.p.subgriseus $(O)$ & MCZ & 68154 \\
\hline VSD163 & P.p. subgriseus $(O)$ & $\mathrm{MCZ}$ & 68161 \\
\hline VSD118 & P.p.subgriseus $(T)$ & $\mathrm{MCZ}$ & 68116 \\
\hline VSD120 & P.p.subgriseus $(T)$ & $\mathrm{MCZ}$ & 68118 \\
\hline VSD122 & P.p. subgriseus $(T)$ & MCZ & 68120 \\
\hline VSD123 & P.p. subgriseus $(\mathrm{T})$ & MCZ & 68121 \\
\hline VSD127 & P.p. subgriseus $(\mathrm{T})$ & $\mathrm{MCZ}$ & 68125 \\
\hline PKBM104 & P.p.trisyllepsis & FLMNH & \\
\hline PKBM1042 & P.p.trisyllepsis & FLMNH & \\
\hline PKBM1077 & P.p.trisyllepsis & FLMNH & \\
\hline PKBM1112 & P.p.trisyllepsis & FLMNH & \\
\hline PKBM145 & P.p.trisyllepsis & FLMNH & \\
\hline
\end{tabular}



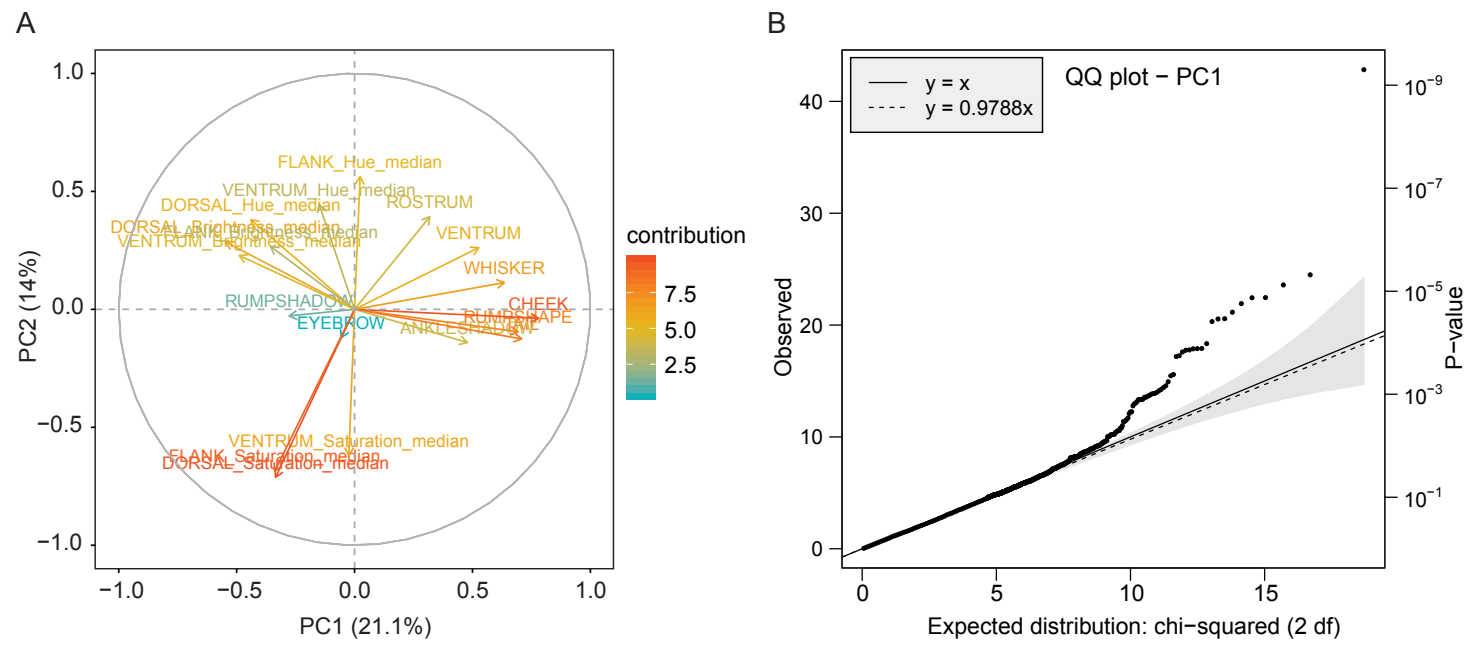

Figure S1. Pigment trait loadings on phenotypic Principal Component Analysis (PCA). A. PCA biplot shows contributions of pigment traits to the first two phenotypic PCs. Percentage values in parentheses correspond to the percent variance explained by each PC. B. Quantile-quantile plot of empirical vs. expected GWAS p-value distributions, indicating no signs of overdispersion or abnormal behavior. 


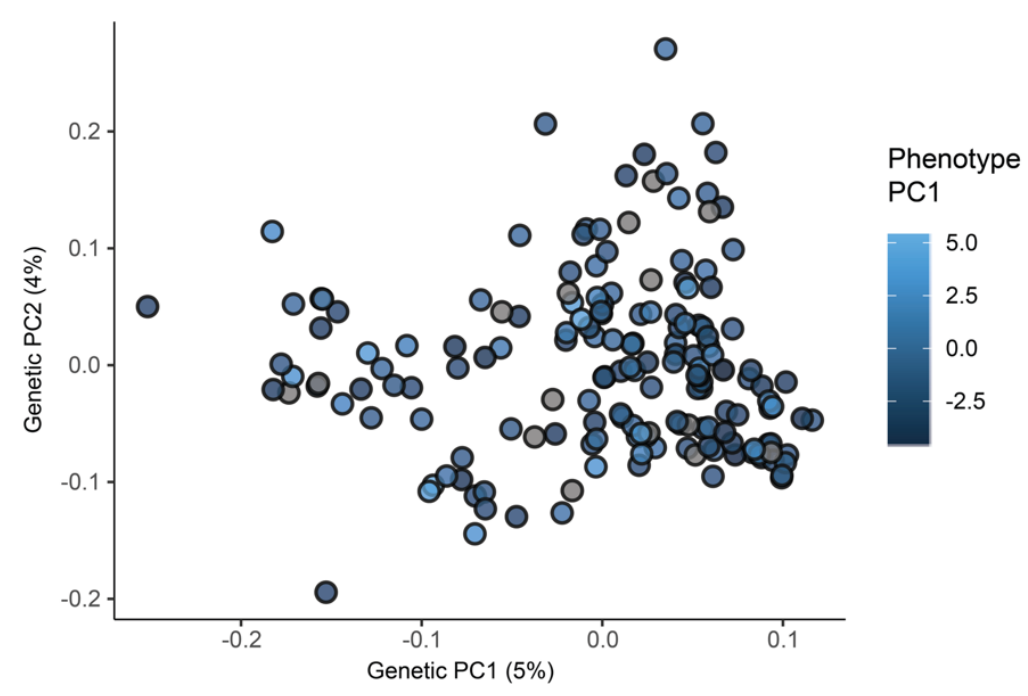

Figure S2. Genetic principal components analysis of the $\boldsymbol{P}$. p. albifrons population. Each dot represents an individual $(\mathrm{N}=168)$. Color approximates phenotypic $\mathrm{PC} 1$ value. Percentage value on each axis corresponds to the percent variance explained by each genetic PC. 


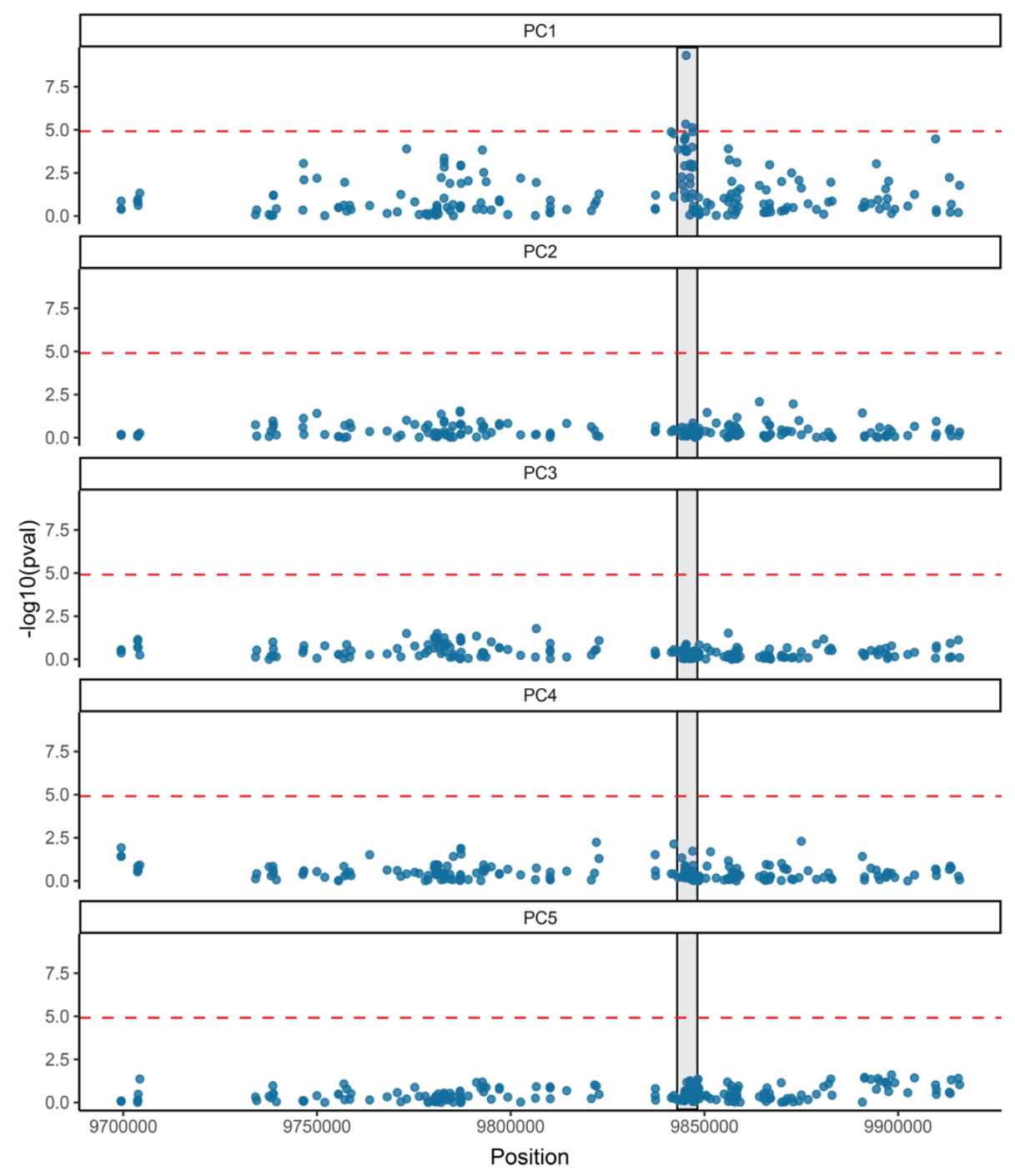

Figure S3. Manhattan plots showing association between phenotype and variation across the $\mathbf{A g o u t i}$ locus. Data for phenotypic PCs (pPCs) 1 to 5 are shown. Dashed red lines indicate genome-wide significant threshold, corrected for number of independent tests (see Methods). Gray bar denotes boundaries of peak association found for pPC1. No other pPCs show a significant association with variants in Agouti. 


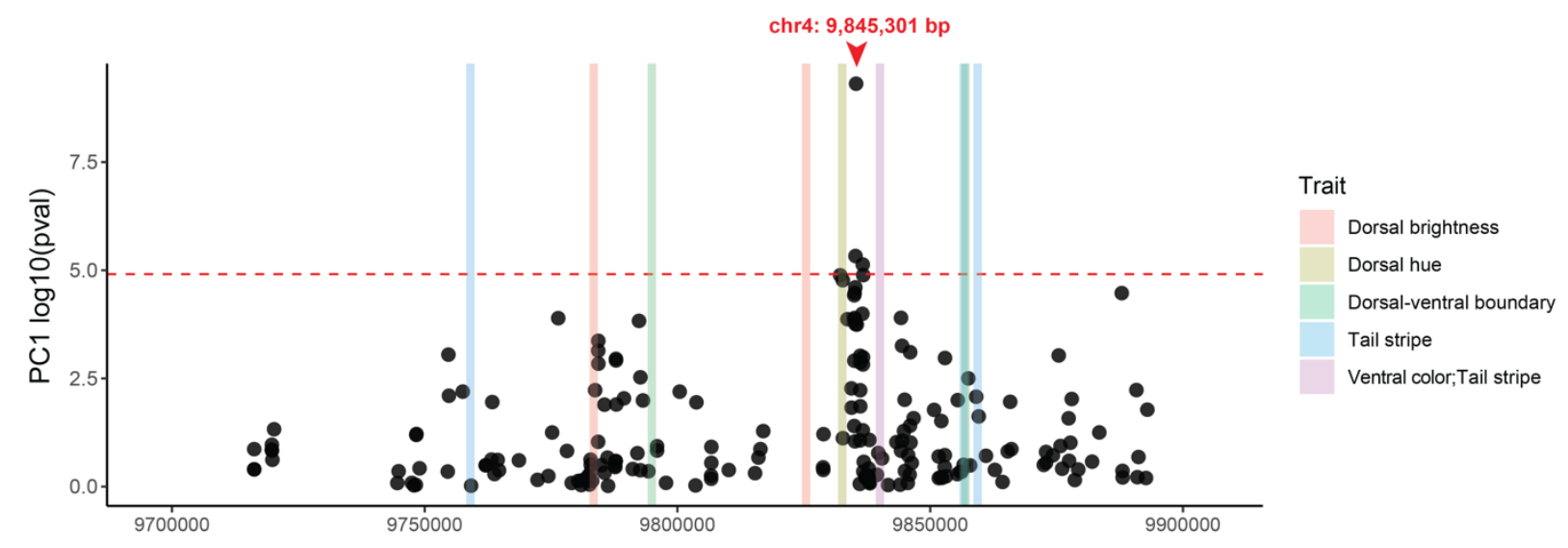

Figure S4. Location of the newly identified regulatory region in relation to previously implicated regions. The top-associated SNP (chr4:9,845,301) is shown in red. Vertical bars indicate regions of Agouti that are significantly associated with pigmentation traits in P. maniculatus, from Linnen et al. (2013). 
A

\section{Agouti}

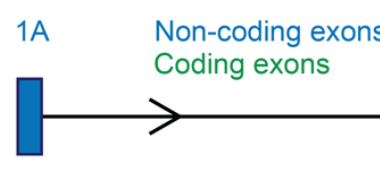

B

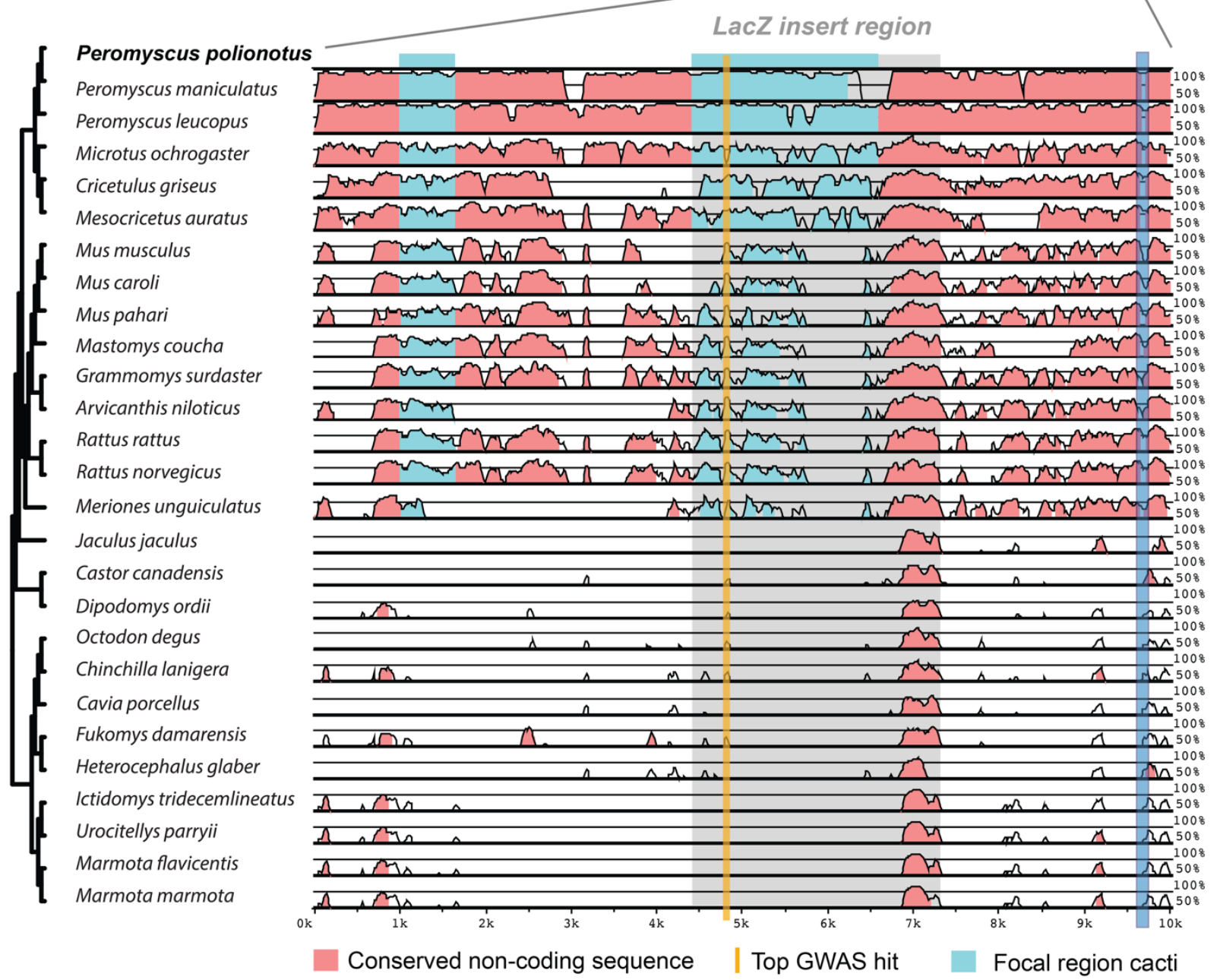

Figure S5. Sequence conservation in Agouti among 27 rodent species. $10 \mathrm{~kb}$ region encompassing the SNP with the strongest association to pPC1 (chr4:9,845,301) denoted in gold. Conserved regions are shown in pink. 'Focal region cacti' (light blue) indicate the regions identified by Saguaro (see Methods; Fig. 5) with a unique topology relative to the rest of the Agouti locus. The $2.6 \mathrm{~kb}$ region used in the lacZ reporter assay (grey) includes the cacti region (light blue), the top associated SNP (gold) and a conserved region (pink). One non-coding exon, 1E, is shown as a landmark (dark blue). 

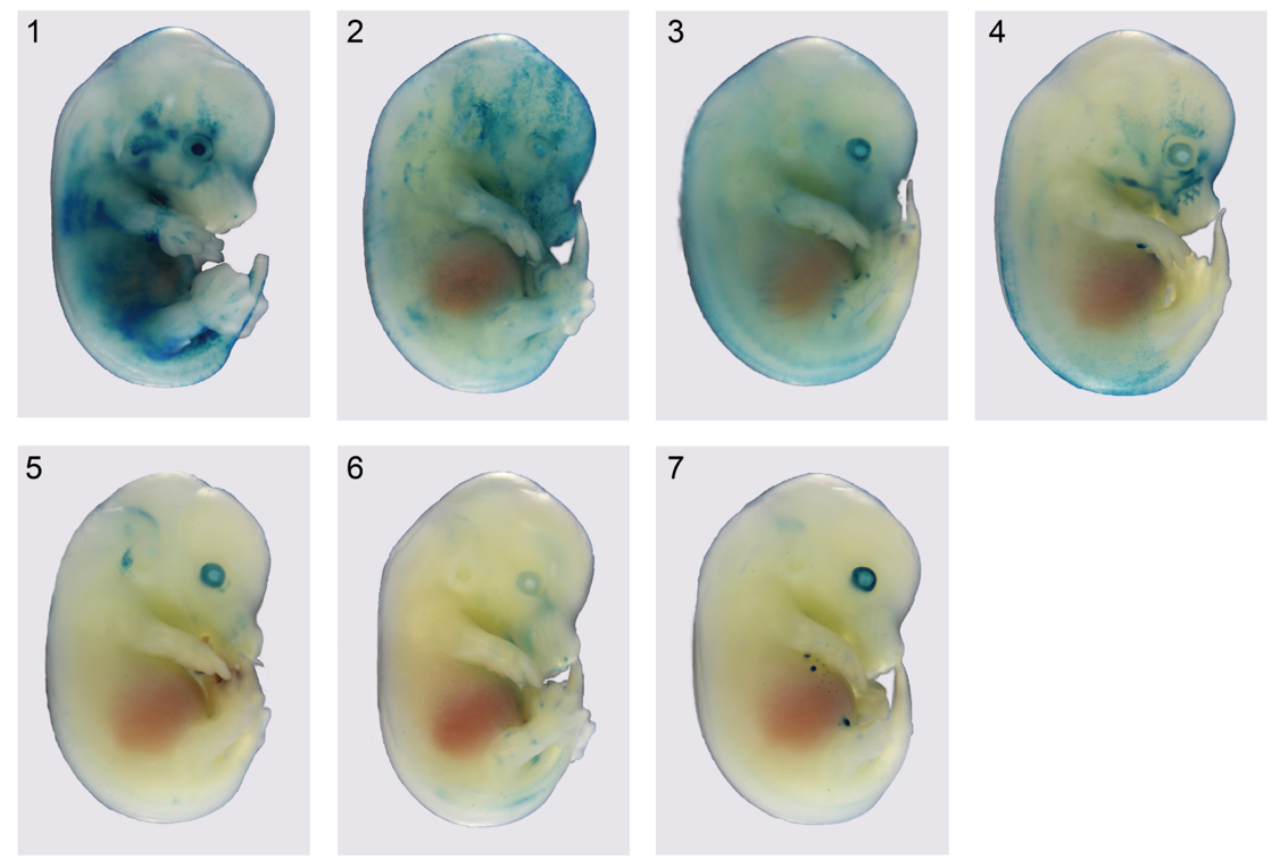

Figure S6. Transgenic embryos with visible skin lacZ expression produced by pronuclear injection of the candidate region-lacZ vector. All embryos are at stage E14.5, PCR-positive for the lac $Z$ vector, and each represents an independent genomic integration event. Blue staining shows lac $Z$ expression and regulatory element activity. 